\title{
Multi-Time Scale Spillover Effect of International Oil Price Fluctuation on China's Stock Markets
}

\author{
Jingran Zhu ${ }^{1,2}$, Qinghua Song ${ }^{2, *(D)}$ and Dalia Streimikiene ${ }^{3, *(D)}$ \\ College of Business, Yancheng Teachers University, Yancheng 224007, China; zhujingran@stu.zuel.edu.cn \\ 2 School of Finance, Zhongnan University of Economics and Law, Wuhan 430073, China \\ 3 Kaunas Faculty, Vilnius University, Muitines 8, LT-44280 Kaunas, Lithuania \\ * Correspondence: qhsong@zuel.edu.cn (Q.S.); dalia.streimikiene@knf.vu.lt (D.S.)
}

Received: 29 July 2020; Accepted: 3 September 2020; Published: 7 September 2020

\begin{abstract}
With the continuous increase of China's foreign-trade dependence on crude oil and the accelerating integration of the international crude oil market and the Chinese finance market, the spillover effect of international oil price fluctuation on China's stock markets increasingly attracts the attention of the public. In order to explore the impact of international oil price fluctuation on China's stock markets and the time-varying spillover differences of industry sectors, this study proposes three research hypotheses and constructs a multi-time scale analysis framework based on wavelet analysis and a time-varying t-Copula model. In this paper, we use the Shanghai Composite Index as the representative of a general trend of the stock market, and we use the stock index of the China Securities Industry as the counterpart of industrial sectors. Based on the data from 5 January 2005 to 31 May 2020, this paper measures and analyzes the spillover effect of international oil price fluctuation on China's stock markets, under different volatility periods. The results show that, firstly, the spillover effect of international oil price fluctuation on the Chinese stock markets is different. In the short and medium volatility period, the changes in international oil price are ahead of the changes in the Chinese stock markets, while the latter is ahead of the former under long-term fluctuations. Secondly, the spillover effect of international oil price fluctuation on China's industry stock indexes is persistent. As the time scale increases, the tail dependency will increase. Finally, the impact of risk events aggravates the volatility of the stock markets in the short-term, while the mid- to long-term impact mainly affects the volatility trend. Investment risk control can make overall arrangement on the basis of the characteristics of oil price impact under different fluctuation stages.
\end{abstract}

Keywords: crude oil price; stock market; spillover effect; wavelet analysis; t-Copula model

\section{Introduction}

Crude oil has the triple attributes of commodity, finance, and politics. Crude oil price changes might directly induce the fluctuation of a macro-economy and even increase the uncertainty of financial market development. Since the 1970s, the spillover effect of oil price changes on financial markets has progressively grown, with an increasing emphasis on the role and financial attributes of crude oil strategic energy sources [1,2]. As an important part of the financial market, the stock market is the weatherglass of the economic and financial development conditions of a country [3]. Recently, the spillover effect of international oil price fluctuation on the stock market has become a research hotspot, as a result of the deep integration of the crude oil and stock markets. Numerous researches have proven that rise in crude oil prices can affect the stock market through real economy, financial investment, and other pathways; however, no consensus has been reached as regards the size and direction of the spillover effect of oil price fluctuation on stock markets [4,5]. Therefore, under the increasing uncertainty in the crude oil market and 
the impact of COVID-19, what are the multi-time -scale-impact differences and evolution characteristics of international oil price fluctuation on China's stock markets? Under different volatility periods, what are the time-varying spillover differences of international oil price fluctuations on Chinese industry sectors? These are the main research questions, which are also the purpose of this article.

China is the second largest global economic entity. In 2019, its total crude oil imports exceeded 500 million tons and showed a foreign-trade dependence of $72 \%$. In the future, the imports and foreign-trade dependence of China on crude oil will increase further. Thus, oil price fluctuation will surely impact China's economy and financial market. Meanwhile, the spillover effect of oil price fluctuation on China's stock markets is highlighted increasingly after some A-stocks were enlisted into the global emerging market index and the Shanghai crude oil futures were launched into the market. The price comparison of Brent spot crude oil and the Shanghai Composite Index from January 1991 to May 2020 is shown in Figure 1. A strong correlation of variation trends exists between the Brent spot crude oil and Shanghai Composite Index. When impacts arise from great risk events (such as the global financial crisis of 2008-2009, the global economic slowdown in 2014-2015, and the COVID-19 outbreak in 2020), the correlation between Brent spot crude oil and the Shanghai Composite Index is increased significantly. This outcome indicates an information-overflow relation between the international crude oil market and China's stock markets, but the size and direction of the spillover effect must be explored further.

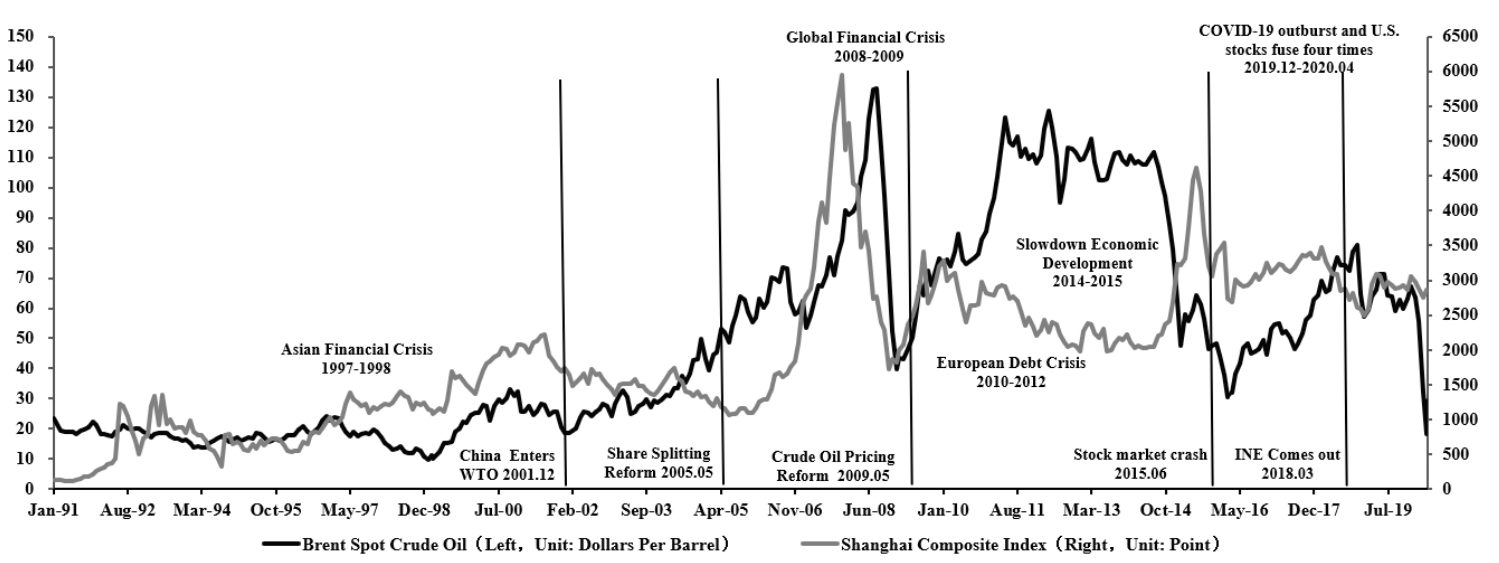

Figure 1. Brent spot price and the Shanghai Composite Index.

According to existing studies, a long-term co-integration relationship exists between international oil price fluctuation and the benefits and fluctuation of China's stock markets. The general overall spillover effect of oil price changes on China's stock markets is increasing gradually, and the differences and time-varying performances of the influences on different industries are highlighted [6-8]. Few investigations have been conducted on the time-varying spillover and tail risk spillover of international oil price fluctuation on overall revenues and the industrial stock price index of those markets according to different fluctuation periods or various time scales. In view of this, the purpose of this paper is to explore the impact of international oil price fluctuation on China's stock markets, under different time scales, and the time-varying spillover differences of international oil price fluctuation on industry sectors, under volatility periods. Therefore, using data on Brent spot crude oil, the Shanghai Composite Index, and the stock index of the China Securities Industry from 5 January 2005 to 31 May 2020, this study conducted a comprehensive analysis of the spillover effect of international oil price fluctuation on China's stock markets by combining wavelet analysis and the Copula model. Furthermore, the time-varying spillover differences of oil price fluctuation on the stock indexes of different industries were analyzed.

Based on the above analysis, in order to better explore the impact of international oil price fluctuation on China's stock market and the time-varying spillover differences of industry sectors, this paper proposes the following hypotheses: 
Hypothesis 1. The impact of risk events will aggravate the spillover effect of international oil price fluctuation on China's stock markets.

Hypothesis 2. With the increase of time scale, the spillover effect of international oil price fluctuation on China's stock markets will be increased.

Hypothesis 3. Under different volatility periods, the spillover effect of international oil price fluctuation on China's industry stock index is different.

The possible marginal contributions of this study are as follows. First, unlike previous studies on the basis of weekly, monthly, and annual data, this work chooses the relatively higher frequency of daily data and investigates the spillover effect of the international crude oil market on China's stock markets and thus provides a more precise orientation of a dynamic spillover effect of oil price changes on China's stock markets. Second, unlike prior independent measurements of the spillover effects of oil price fluctuation on the composite index or industrial stock price index, this research included comprehensive benefits and industrial differences into a uniform analysis framework and discussed the comprehensive benefit spillover and tail risk spillover of oil price fluctuation on China's stock markets by combining wavelet analysis and the Copula model. This approach expanded the correlation analysis of the spillover effect. Finally, instead of using a single time scale, this study divided the sample interval into short-term, middle-term, and long-term periods, evaluated the spillover effect under different time scales, explored the time-frequency domain differences of oil price fluctuation on China's stock markets, and enriched relevant studies on the influences of the time-frequency domain.

The remainder of this study is organized as follows: Section 2 is the literature review, which mainly summarizes and evaluates studies concerning the influences of oil price fluctuation on the stock market. Section 3 describes the main models, variables, and data. Section 4 involves the result analysis. Empirical research contents are introduced and robustness is tested. Section 5 discusses the empirical research results. Section 6 presents the conclusions of this work.

\section{Literature Review}

Existing studies on the spillover effect of oil price fluctuation on stock markets mainly focus on four aspects. The first one involves the theoretical and transmission mechanisms of oil price fluctuation on stock markets. Sakellaris [9] constructed a dynamically optimized capital accumulation model and found that oil price fluctuation could significantly influence changes of the yield advantages of stocks. According to Sakellaris's model of general equilibrium theory expansion and the investment model, Wei [10] constructed a theoretical analysis model between energy element price changes and stock benefit fluctuations. He found that a $10 \%$ reduction of the stock market value in the United States during 1973-1974 could be interpreted by an $80 \%$ rise of crude oil price. Antonakakis et al. [11] further discovered that, for a non-oil producing country, the rise of crude oil price leads to an increase of enterprise costs and decrease of cash flow, thereby resulting in the share drop. The rise of the crude oil price might intensify inflation, cause the growth of the stock discount rate, and induce stock price fluctuation [12]. In contrast, the variation trends of oil price fluctuation and stock market value are generally the same in oil-producing countries [13,14].

The second one refers to the size and direction of the spillover effect of international oil price fluctuation on stock markets. Some scholars believe that oil price fluctuation had no spillover effect on stock markets. Huang et al. [15] found that neither spot crude oil nor crude oil futures can impact stock markets in the United States. However, this finding contradicts those of most researchers. The majority of scholars believe that a spillover effect occurs between oil price fluctuation and the stock market. Through an empirical study method, Jones and Kaul [16] first confirmed that oil price fluctuation after WWII had a negative spillover effect on stock markets in the United States, the UK, Japan, and Canada. Following Jones and Kaul [16], Park and Ratti [17] distinguished between crude oil importer and 
exporter countries and examined the data of 13 European countries and American. They found that changes in crude oil price had negative impacts on the stock markets of petroleum-importer countries but had positive impacts on petroleum-export countries [17]. By using the generalized autoregressive conditional heteroscedasticity (GARCH) model, the Granger causality test, and a vector autoregression model, follow-up studies confirmed that oil price fluctuation had an evident spillover effect on the stock markets in developed countries and emerging economic entities [11,18-20].

The third one is the spillover effect of different types of oil price impacts. Kilian [21] was the first to divide oil price impact, from the perspectives of supply and demand, into crude oil supply, global total demand, and crude-oil-specific-demand impacts. Kang and Ratti [22] and Broadstock and Filis [23] further discovered that the impacts of crude oil demands on a stock market were stronger than those of the supply and spillover effects of oil price fluctuation among different industries. Unlike Kilian [21], Ready [24] divided the effects of oil price fluctuation into the demand, supply, and risk impacts from the perspective of enterprise production. The author verified that the spillover effect of supply and risk impacts on the stock market of the United States enhances gradually, whereas the effect of the demand impact declined to some extent. Ahmed et al. [4] further discovered, by using the method of Ready [24], that the spillover effects of the risk and demand impacts are relatively stronger for crude-oil-importer countries.

The fourth one involves the dynamic and time-varying spillover effects of oil price impacts. The asymmetric impacts and time-varying spillover differences of oil price fluctuation on stock market have been highlighted gradually since 2010. Relevant studies attracted wide attention [25-28]. Aloui et al. [25] proved, by a continuous wavelet analysis, that the time-varying spillover effect of oil price fluctuation on the stock markets of developed countries is significant. Jia et al. [26] proved, by wavelet transformation, that an international oil price fluctuation had multi-time scales of spillover effects on Daqing oil price and the petroleum industrial stock index returns of China. Using data of China's and Asian stock markets, Huang et al. [27] and Sarwar et al. [28] found, by combining wavelet analysis and the Copula model, that an international oil price fluctuation had variations in its time-varying spillover effect on industrial indexes in different countries.

To sum up, the existing literature discusses the spillover effect of international oil price fluctuation on the stock markets from four aspects: theoretical transmission mechanism, spillover size and direction, different types of oil price shocks, and time-varying spillover differences. However, most of them explore spillover effects from a relatively static perspective, and there are relatively few studies that clearly distinguish different time scales or different volatility periods. At the same time, there are relatively few literatures on the comparative analysis of international oil price fluctuations on the stock markets as a whole and the spillover differences of different industry sectors. In view of this, from the perspective of multiple time scales, this paper takes international oil price and Chinese stock market as the research object, brings the comprehensive stock index and industry differences into the unified analysis framework, and comprehensively uses wavelet analysis and copula model to comprehensively measure the comprehensive impact of international oil price fluctuation on China's stock market and the time-varying spillover differences on industry sectors.

\section{Models and Data}

\subsection{Model Construction}

In order to better analyze the research content of this paper and discuss the above three research hypotheses, with reference to the methods of Fang and Egan [6], Yahya et al. [29] and Feng et al. [30], a multi-time scale analysis framework was constructed on the basis of wavelet analysis and a Copula function model. First, the revenue sequences of the oil price and stock index were decomposed according to the maximum overlapping discrete wavelet transformation (MODWT). Moreover, the correlations of basic data needed for multi-time scale analysis were analyzed. Second, the multi-time scale spillover effect and time-frequency domain spillover difference of oil price fluctuation on the Shanghai Composite 
Index were explored through the cross wavelet and wavelet coherence method. Finally, the optimal marginal distribution was estimated on the basis of the autoregressive moving average-exponential generalized autoregressive conditional heteroskedasticity (ARMA-EGARCH) model. Accordingly, the multi-time scale effect and dynamic spillover differences of oil price fluctuation on China's industrial stock index were evaluated using the time-varying $\mathrm{t}$-Copula model. The major models are introduced as follows.

\subsubsection{Wavelet Analysis Model}

\section{(1) MODWT}

The MODWT is a highly redundant non-orthogonal wavelet transformation and avoids the influences of discrete wavelet transform on the selection of different starting points of a time series. This technique is applicable for the multi-time scale analysis of a financial time series. The basic content is introduced as follows.

First, a filter was set. Suppose the sample number of the original time series is $N$; then the wavelet filter of MODWT is $\left\{\widetilde{h}_{l}\right\}\left(\widehat{h}_{l}=h_{l} / \sqrt{2}\right)$, and the scale filter is $\left\{\widetilde{\mathrm{g}}_{l}\right\}\left(\widetilde{\mathrm{g}}_{l}=g_{l} / \sqrt{2}=(-1)^{l+1} \widetilde{h}_{L-1-t}\right)$. Then, $\left\{\widetilde{h}_{l}\right\}$ and $\left\{\widetilde{\mathrm{g}}_{l}\right\}$ have the following properties.

$$
\begin{gathered}
\sum_{l=0}^{L-1} \widetilde{h}_{l}=0, \sum_{l=0}^{L-1} \widetilde{h}_{l}^{2}=0.5, \sum_{l=0}^{L-1} \widetilde{h}_{l} \widetilde{h}_{l+2 n}=0, \\
\sum_{l=0}^{L-1} \widetilde{\mathrm{g}}_{l}=1, \sum_{l=0}^{L-1} \widetilde{\mathrm{g}}_{l}^{2}=0.5, \sum_{l=-\infty}^{\infty} \widetilde{\mathrm{g}}_{l} \widetilde{\mathrm{g}}_{l+2 n}=0, \\
\sum_{l=-\infty}^{\infty} \widetilde{\mathrm{g}}_{l} \widetilde{h}_{l+2 n}=0 .
\end{gathered}
$$

Second, the wavelet and scale coefficients are determined. Suppose $X=\left\{X_{t}: t=0, \cdots, N-1\right\}$ is an original time series with a sample size of $N$. The series is defined as follows:

$$
\widetilde{W}_{1, t}=\sum_{l=0}^{L-1} \widetilde{h}_{l} X_{t-l \bmod N}, \widetilde{V}_{1, t}=\sum_{l=0}^{L-1} \widetilde{\mathrm{g}}_{l} X_{t-l \bmod N}, t=0,1, \cdots, N-1 .
$$

where $\widetilde{W}_{1, t}$ and $\widetilde{V}_{1, t}$ are the first layers of the wavelet and scale coefficient of MODWT, respectively. For a time series $X$ with any time, the wavelet and scale coefficients of the jth layer of the MODWT are generally vectors $\widetilde{W}_{j}$ and $\widetilde{V}_{j}$, respectively. Then, the elements contained in $\widetilde{W}_{j}$ and $\widetilde{V}_{j}$ are as follows:

$$
\widetilde{W}_{j, t}=\sum_{l=0}^{L-1} \widetilde{h}_{j, l} X_{t-l \bmod N}, \widetilde{V}_{j, t}=\sum_{l=0}^{L-1} \widetilde{\mathrm{g}}_{g, l} X_{t-l \bmod N}, t=0,1, \cdots, N-1,
$$

where $\widetilde{h}_{j, l}=h_{j, l} / 2^{j / 2}$, and $\widetilde{\mathrm{g}}_{g, l}=g_{j, l} / 2^{j / 2}$. Filters $\left\{\widetilde{h}_{j, l}\right\}$ and $\left\{\widetilde{\mathrm{g}}_{g, l}\right\}$ are the wavelet and scale filters of the jth layer. The width is $L_{j}=\left(2^{j}-1\right)(L-1)+1$, and the corresponding scale is $\lambda_{j}=2^{j-1}$.

(2) Continuous wavelet transform

Continuous wavelet transform refers to the specific mother wavelet projected by the original time series $x(t)$ onto a two-dimensional same scale. For the time series $x(t)$, the continuous wavelet transform of the mother wavelet is as follows:

$$
W_{x}(\alpha, s)=\frac{1}{\sqrt{s}} \int_{-\infty}^{+\infty} x(t) \varphi\left(\frac{t-\alpha}{s}\right) d t
$$


Furthermore, for any $x(t) \subset L^{2}(R)$, the expressions after the reconstruction and decomposition of the continuous wavelet transform is as follows:

$$
x(t)=\frac{1}{C_{\varphi}}\left[\int_{-\infty}^{+\infty} W_{x}(\alpha, s) \varphi_{\alpha, s}(t) d u\right] \frac{d s}{s^{2}}, s>0 .
$$

Accordingly, the variance of the continuous wavelet power spectral analysis can be expressed as follows:

$$
\|x\|^{2}=\frac{1}{C_{\varphi}}\left[\int_{0}^{+\infty}\left|W_{x}(\alpha, s)\right|^{2} d u\right] \frac{d s}{s^{2}}, s>0,
$$

where $\left|W_{x}(\alpha, s)\right|^{2}$ is the wavelet power spectrum and refers to changes of the local variance under different ratio scales, $x(t)$. On the basis of Monte Carlo simulation, Torrence and Compo [31] calculated a local wavelet power spectrum, which is expressed as follows:

$$
D\left(\frac{\left|W_{x}(s)\right|^{2}}{\sigma_{x}^{2}}<p\right)=\frac{1}{2} P_{f} x_{v}^{2}
$$

where $P_{f}$ refers to the mean frequency spectrum at the Fourier frequency, $f$, under each time point, $t$, and scale, $s$. The corresponding $s$ and $f$ are reciprocals.

(3) Cross wavelet transform and wavelet coherence

The cross wavelet transform is a multi-time scale analysis technology that combines the continuous wavelet transform and cross spectral analysis and can better explain the phase structure and correlation between two time series in a time-frequency domain better. The cross wavelet transform is defined as follows.

Suppose the wavelet functions of two time series are $x(t)$ and $y(t)$. Then, the wavelet cross spectrum $W_{x, y}(\alpha, s)$ can be expressed as follows:

$$
W_{x, y}(\alpha, s)=W_{x}(\alpha, s) W_{y}^{*}(\alpha, s)
$$

where $\alpha$ refers to the position parameter, $s$ refers to the scale parameter, and $W_{y}^{*}(\alpha, s)$ is the complex conjugate of $W_{y}(\alpha, s)$. The cross wavelet spectrum $W_{x y}(\alpha, s)$ refers to the energy resonance and local covariance of two time series under a specific frequency at any time points.

The power spectrum of the cross wavelet transform between two time sequences is expressed as follows:

$$
D\left(\frac{\left|W_{x}(s) W_{y}^{*}(s)\right|}{\sigma_{x} \sigma_{y}}<p\right)=\frac{Z_{v}(p)}{v} \sqrt{P_{f}^{x} P_{f^{\prime}}^{y}}
$$

where $P_{f}^{x}$ and $P_{f}^{y}$ are the wavelet power spectra of $x(t)$ and $y(t) ; Z_{v}(p)$ is the confidence level related to the probability density function (PDF). The PDF is defined by the square root of the product of two $\chi^{2}$ distributions.

Torrence and Compo [31] further proposed wavelet coherence and phase difference. Specifically, wavelet coherence is the mean of the smooth cross wavelet power spectrum of each chosen time series and can be used to measure the correlation of two time series in different time-frequency domains. The expression of the wavelet coherence coefficient is as follows:

$$
R_{x y}^{2}(\alpha, s)=\frac{\mid S\left(\left.s^{-1} W_{x y}(\alpha, s)\right|^{2}\right.}{S\left(s ^ { - 1 } | W _ { x } ( \alpha , s ) | ^ { 2 } S \left(s^{-1}\left|W_{y}(\alpha, s)\right|^{2}\right.\right.}
$$


The value of the wavelet coherence coefficient $R_{x y}^{2}(\alpha, s)$ is [0,1]. If the correlation coefficient is closer to 1 , then the correlation degree is higher. The wavelet coherence coefficient is the squared value that cannot distinguish between positive and negative correlations. With reference to the method of Yang et al. [32], this work analyzed the correlation and causal relationship of different time series by phase difference. The phase differences of the wavelet functions $x(t)$ and $y(t)$ are defined as follows:

$$
\varphi_{x y}(\alpha, s)=\tan ^{-1}\left(\frac{\supset\left\{S\left(s^{-1} W_{x y}(\alpha, s)\right\}\right.}{R\left\{S\left(s^{-1} W_{x y}(\alpha, s)\right\}\right.}\right),
$$

where $\varphi_{x y}(\alpha, s)$ refers to the phase relation of the vibration of two time series and is valued between $[-\pi, \pi]$. When $\varphi_{x y}(\alpha, s)=0$, no phase difference occurs between two time series. When $\varphi_{x y}(\alpha, s)$ values are between $[-\pi / 2, \pi / 2]$, two time series are positively correlated with homonymous movement; otherwise, they are negatively correlated with adverse movement.

\subsubsection{Marginal Distribution Estimation Model and Time-Varying t-Copula Model}

\section{(1) Marginal distribution estimation model}

The marginal distribution estimation is the basis of constructing the Copula model. Due to the financial time series having characteristics of fluctuation grouping, sharp peak, and heavy tails, GARCH models are usually used to estimate the marginal distribution. However, the basic GARCH model cannot fully describe the leverage effect of financial series. In order to analyze the asymmetric spillover of international crude oil on the stock indexes of China Securities Industry more comprehensively, this paper chooses the EGARCH model, which relaxes the non-negative restrictions on the model parameters, as the basic model. At the same time, in order to better analyze the multi-time scale effect, this paper introduces ARMA model, and finally an ARMA-EGARCH model was constructed for marginal distribution estimation [33]. Based on Appendix A Table A1, the minimum Akaike information criterion (AIC) and Schwarz criterion, as well as the maximum log-likelihood function, are found in the EGARCH model; therefore, the ARMA(1,0)-EGARCH $(1,1)$ model is the marginal distribution estimation model which is most appropriate in this study. The specific model is as follows:

$$
\left\{\begin{array}{c}
x_{n t}=\mu+\theta x_{n, t-1}+\varepsilon_{n t} \\
\varepsilon_{n t}=\sqrt{h_{n t}} \xi_{n t}, \xi_{n t} \sim \operatorname{iid}(0,1) \\
\ln h_{n t}=\omega+\alpha\left|\varepsilon_{n, t-1} / \sqrt{h_{n, t-1}}\right|+\beta \varepsilon_{n, t-1} / \sqrt{h_{n, t-1}}+\gamma \ln h_{n, t-1}
\end{array} .\right.
$$

In the first equation of Equation (14), $\mu$ is the intercept term. $\theta$ is the coefficient of $\operatorname{AR}(1)$ and reflects the influence degree of the phase-I lag on the previous phase. $\varepsilon_{n t}$ is the probability distribution chosen according to the characteristics of different time series. In the second equation, $h_{n t}$ is the conditional variance of the time series $n$ at $t$, and $\xi_{n t}$ is the residual error of time series $n$ at $t$. In the third equation, $\omega$ is the intercept term, $\alpha$ is the autoregressive conditional heteroskedasticity (ARCH) coefficient, $\beta$ is the coefficient of asymmetric term, and $\gamma$ is the coefficient of the GARCH coefficient.

(2) Time-varying t-Copula model

According to marginal distribution estimation, the binary time-varying $\mathrm{t}$-Copula model was chosen as the basic model with references to Yahya et al. [29] and Bekiros et al. [34]. The basic contents are introduced as follows.

First, the joint distribution function and joint probability density of the Copula model are determined. Let $X_{t}$ and $Y_{t}$ be the benefit sequences of the original price and industrial stock index. Meanwhile, let $F_{X}(x)$ and $F_{Y}(y)$ be the marginal distribution function of the two time series. Then, the joint distribution function is $F_{X Y}(x y)$. According to the Sklar theorem and deduction, we get the following:

$$
F_{X Y}(x y)=C\left(F_{X}(x), F_{Y}(y)\right)
$$


Let $u=F_{X}(x)$ and $v=F_{Y}(y)$. Then, $C(u, v)$ is a bivariate Copula function. The Copula density of $C(u, v)$ is $c(u, v)=\partial^{2} C(u, v) / \partial u \partial v$. Furthermore, the joint probability density of $F_{X Y}(x y)$ is as follows:

$$
F_{X Y}(x y)=c(u, v) f_{X}(x) f_{Y}(y)
$$

where $f_{X}(x)$ and $f_{Y}(y)$ are the marginal densities of variables $x$ and $y$.

Second, the binary time-varying t-Copula function is constructed. On the basis of the determination of the joint distribution function and joint probability density, the binary time-varying t-Copula model can be expressed as follows:

$$
C_{d, \rho}(u, v)=t_{d, \rho}\left(t_{d}^{-1}(u), t_{d}^{-1}(v),\right.
$$

where $\rho$ is the correlation coefficient and $d$ is the degree of freedom (DOF). Furthermore, the general multivariate time-varying t-Copula can be expressed as follows:

$$
C_{d, \rho}\left(u_{1}, u_{2}, \cdots, u_{n}\right)=t_{d, \rho}\left(t_{d}^{-1}\left(u_{1}\right), t_{d}^{-1}\left(u_{2}\right), \cdots, t_{d}^{-1}\left(u_{n}\right)\right),
$$

where $t_{d}^{-1}$ is the reciprocal of univariate distribution, and $t_{d, \rho}$ refers to the multi-elements $t$ distribution that uses $\rho$ as the correlation matrix. For dynamic analysis, the linear correlation coefficient $(\rho)$ was replaced by a dynamic conditional correlation in this work with references to Berger and Uddin [35] to capture the dynamic dependence and spillover relationship between oil price and industrial stock index. The expressions are as follows:

$$
\begin{gathered}
R_{t}=\operatorname{diag}\left(\widetilde{Q}_{t}\right)^{-1} Q_{t} \operatorname{diag}\left(Q_{t}\right)^{-1}, \\
Q_{t}=(1-\alpha-\beta) \bar{Q}+\alpha \varepsilon_{t-1} \varepsilon_{t-1}^{\prime}+\beta Q_{t-1},
\end{gathered}
$$

where $\bar{Q}$ is the sample covariance of $\varepsilon_{t}$, and $\widetilde{Q}_{t}$ is a $\rho \times \rho$-order matrix with the $Q_{t}$ of square root of one diagonal element.

\subsection{Variable and Data}

In this study, Brent spot crude oil (Brent), Shanghai Composite Index (SSEC), and the China Securities Industry Stock Index were chosen as samples. Brent spot crude oil price is an international benchmark for oil prices. Among $60 \%$ of countries that import oil from China use the Brent crude oil price as the benchmark oil price, and the Brent has a certain representativeness. The Shanghai Composite Index covers all A and B stocks on the Shanghai Stock Exchange and can fully reflect the general operation trend of China's stock markets fully. The stock index of the China Securities Industry (CSI) contains indexes of 10 industries, including CSI-energy (CSIE), CSI-material (CSIMA) CSI-industry (CSII), CSI-optional (CSIO), CSI-consumption (CSIC), CSI-medicine (CSIME), CSI-finance (CSIF), CSI-information (CSIINF), CSI-telecommunication (CSIT), and CSI-public use (CSIPU). All data were collected from the Wind database.

The sample interval was determined from 5 January 2005 to 31 May 2020. A total of 3595 groups of sample values were gained after missing data caused by holidays and different traction times. In the investigation stage, great risk events, including the global financial crisis of 2008-2009, the European debt crisis during 2010-2012, the crude oil price drop since 2014, the COVID-19 epidemic in 2020, and four stock meltdowns of the United States, were covered. With considerations for data comparability, the logarithmic difference of all data was implemented, thereby obtaining the logarithmic return sequence of different variables. The calculation method is $r_{i, t}=\ln \left(p_{i, t} / p_{i, t-1}\right)=\ln p_{i, t}-\ln p_{i, t-1}$, where $r_{i, t}$ is the logarithmic rate of return, and $p_{i, t}$ is the daily closing price. 


\section{Results Analysis}

\subsection{Descriptive Statistical Analysis}

The descriptive statistical results of Brent spot crude oil and stock index are shown in Table 1. CSI-consumption presents the maximum average yield $(0.081 \%)$, and Brent spot crude oil shows the minimum average yield $(0.006 \%)$. In the stock index part, CSI-information has the maximum standard deviation (SD) (2.263\%), and the Shanghai Composite Index presents the minimum SD (1.663\%). In addition to Brent, the yield sequences of all stock indexes demonstrate a left-skewed distribution. The peaks of all yield sequences are higher than 3, thereby indicating that all variables have evident sharp peaks and tails. The Jarque-Bera statistics, Ljung-Box test statistics, and Lagrange-Multiplier statistics all rejected the null hypothesis significantly under the $1 \%$ level of significance. Thus, all variables fail to obey a normal distribution and conditional heteroscedasticity and autocorrelation are present. Therefore, a marginal distribution estimation can be reasonably made on the basis of the ARMA-GARCH model. The augmented dickey-fuller (ADF) and Phillips-Perron (PP) tests also reject the null hypothesis significantly. Therefore, all benefit sequences are stationary and conform to the requirements of time series analysis.

Table 1. Descriptive statistics.

\begin{tabular}{|c|c|c|c|c|c|c|c|}
\hline Name & Mean (\%) & SD (\%) & Median (\%) & Max & Min & Skewness & Kurtosis \\
\hline SSEC & 0.023 & 1.663 & 0.075 & 0.090 & -0.128 & -0.591 & 8.188 \\
\hline CSIMA & 0.025 & 2.043 & 0.129 & 0.087 & -0.130 & -0.660 & 6.219 \\
\hline CSII & 0.027 & 1.929 & 0.105 & 0.095 & -0.130 & -0.679 & 7.089 \\
\hline CSIO & 0.044 & 1.927 & 0.120 & 0.106 & -0.125 & -0.681 & 6.745 \\
\hline CSIME & 0.069 & 1.913 & 0.118 & 0.112 & -0.128 & -0.541 & 6.618 \\
\hline CSIF & 0.049 & 1.968 & 0.020 & 0.097 & -0.144 & -0.272 & 7.188 \\
\hline CSIIN & 0.044 & 2.263 & 0.191 & 0.095 & -0.118 & -0.643 & 5.331 \\
\hline CSIT & 0.045 & 2.216 & 0.131 & 0.095 & -0.127 & -0.481 & 6.015 \\
\hline CSIPU & 0.016 & 1.735 & 0.055 & 0.083 & -0.132 & -0.765 & 8.069 \\
\hline CSIE & 3595 & $1738.687 * * *$ & $39.405^{* * *}$ & $1014.757^{* * *}$ & $328.398^{* * *}$ & $-21.881^{* * *}$ & $-58.712 * * *$ \\
\hline CSIMA & 3595 & $1812.970 * * *$ & $39.263^{* * *}$ & $1364.110 * * *$ & $411.244^{* * *}$ & $-27.221^{* * *}$ & $-57.786^{* * *}$ \\
\hline CSII & 3595 & $2780.631^{* * *}$ & $35.422 * * *$ & $1722.179^{* * *}$ & $476.589 * * *$ & $-25.627^{* * *}$ & $-57.599 * * *$ \\
\hline CSIO & 3595 & $2379.025 * * *$ & $30.749 * * *$ & $1357.891 * * *$ & $410.318^{* * *}$ & $-28.177 * * *$ & $-58.147 * * *$ \\
\hline CSIC & 3595 & $1543.140^{* * *}$ & $37.178^{* * *}$ & $1291.039^{* * *}$ & $403.570^{* * *}$ & $-26.933^{* * *}$ & $-57.792 * * *$ \\
\hline CSIME & 3595 & $2135.775 * * *$ & $49.503 * * *$ & $1374.190 * * *$ & $407.636^{* * *}$ & $-12.462 * * *$ & $-57.487 * * *$ \\
\hline CSIF & 3595 & $2671.719 * * *$ & $55.475^{* * *}$ & $1223.606^{* * *}$ & $392.147^{* * *}$ & $-23.146^{* * *}$ & $-60.844^{* * *}$ \\
\hline CSIIN & 3595 & $1061.952 * * *$ & $19.713^{* * *}$ & $1375.198 * * *$ & $408.505^{* * *}$ & $-33.114^{* * *}$ & $-57.861 * * *$ \\
\hline CSIT & 3595 & $1499.983 * * *$ & $27.423 * * *$ & $1430.055^{* * *}$ & $448.300^{* * *}$ & $-28.560 * * *$ & $-59.501 * * *$ \\
\hline CSIPU & 3595 & $4199.110^{* * *}$ & $41.764^{* * *}$ & $2258.069^{* * *}$ & $562.643^{* * *}$ & $-26.553^{* * *}$ & $-58.378^{* * *}$ \\
\hline
\end{tabular}

Notes: $\mathrm{Q}(20)$ and $\mathrm{Q}^{2}(20)$ correspond to the Ljung-Box test statistics for serial autocorrelation on returns and squared returns with 20 lags. ARCH(20) provides the statistics of the Engle (1982) test for conditional heteroscedasticity with 20 lags. The ADF and PP Tests for unit root $t$ in the level with intercept in the test equation. ${ }^{* * *}$ represents statistical significance at the $1 \%$ level. SSEC = Shanghai Composite Index; CSI = China Securities Industry; CSIE = CSI-energy; CSIMA = CSI-material; CSII = CSI-industry; CSIO = CSI-optional; CSIC = CSI-consumption; CSIME = CSI-medicine; CSIF $=$ CSI-finance; CSIINF = CSI-information; CSIT = CSI-telecommunication; CSIPU = CSI-public use .

\subsection{Multi-Time scale Decomposition of International Oil Price and China's Stock Index According to MODWT}

4.2.1. Maximum Overlapping Discrete Wavelet Decomposition of Brent Spot Crude Oil and the Stock Index

To assure maximal integrity of sample information, all yield sequences were decomposed into eight-time scales by using the minimum asymmetric wavelet filter (LA) of Daubechies [36], and the sequences were presented in the integer powers of 2. Specifically, the scales denote the following periods: Scale 1, 2-4 days; Scale 2, 4-8 days; Scale 3, 8-16 days; Scale 4, 16-32 days; Scale 5, 32-64 days; 
Scale 6, 64-128 days; Scale 7, 128-256 days; and Scale 8, 256-512 days. Short-term fluctuation occurs from Scales 1 to 3. Mid-term fluctuation occurs from Scales 4 to 5 . Long-term fluctuation occurs from Scales 6 to 8 .

In this study, Brent spot crude oil, the Shanghai Composite Index, and CSI-energy were chosen as examples in the following analysis (Figures 2-4). Each figure has nine small diagrams: the original yield sequence diagram and eight decomposed time scale diagrams. First, both Brent spot crude oil and stock index show violent short-term fluctuation (Scales 1-3). With the increase of time scales, the fluctuation amplitude and fluctuation frequency weaken gradually. Second, in view of a single time dimension (the original yield sequence), both Brent spot crude oil and stock index fluctuated violently during the global financial crisis in 2008-2010, the global economic slowdown in 2015-2016, and the COVID-19 epidemic outburst in early 2020. This outcome reveals that the fluctuation of the crude oil market and stock markets will be intensified upon impacts from great risk events [14,37]. Third, in view of a multi-time scale, a short-term fluctuation aggregation is relatively strong, and the middle-term and long-term fluctuation trends slow down gradually upon the impacts of key events. Hence, risk events might cause impacts to short-term fluctuation, but they influence long-term variation trend relatively slightly, thereby indicating a certain degree of association between the crude oil price and stock index. Finally, the fluctuation range under Scale 1 is $-0.1 \sim 0.1$ and the fluctuation range under Scales 2 and 3 is $-0.05 \sim 0.05$. The fluctuation ranges from Scales 4 to 8 further narrows. Changes of the fluctuation amplitude indicate that the decomposition components under the short term will intensify the fluctuation amplitude, and under the middle and long terms, they influence the fluctuation trend [27]. The above analysis verifies Hypothesis 1.
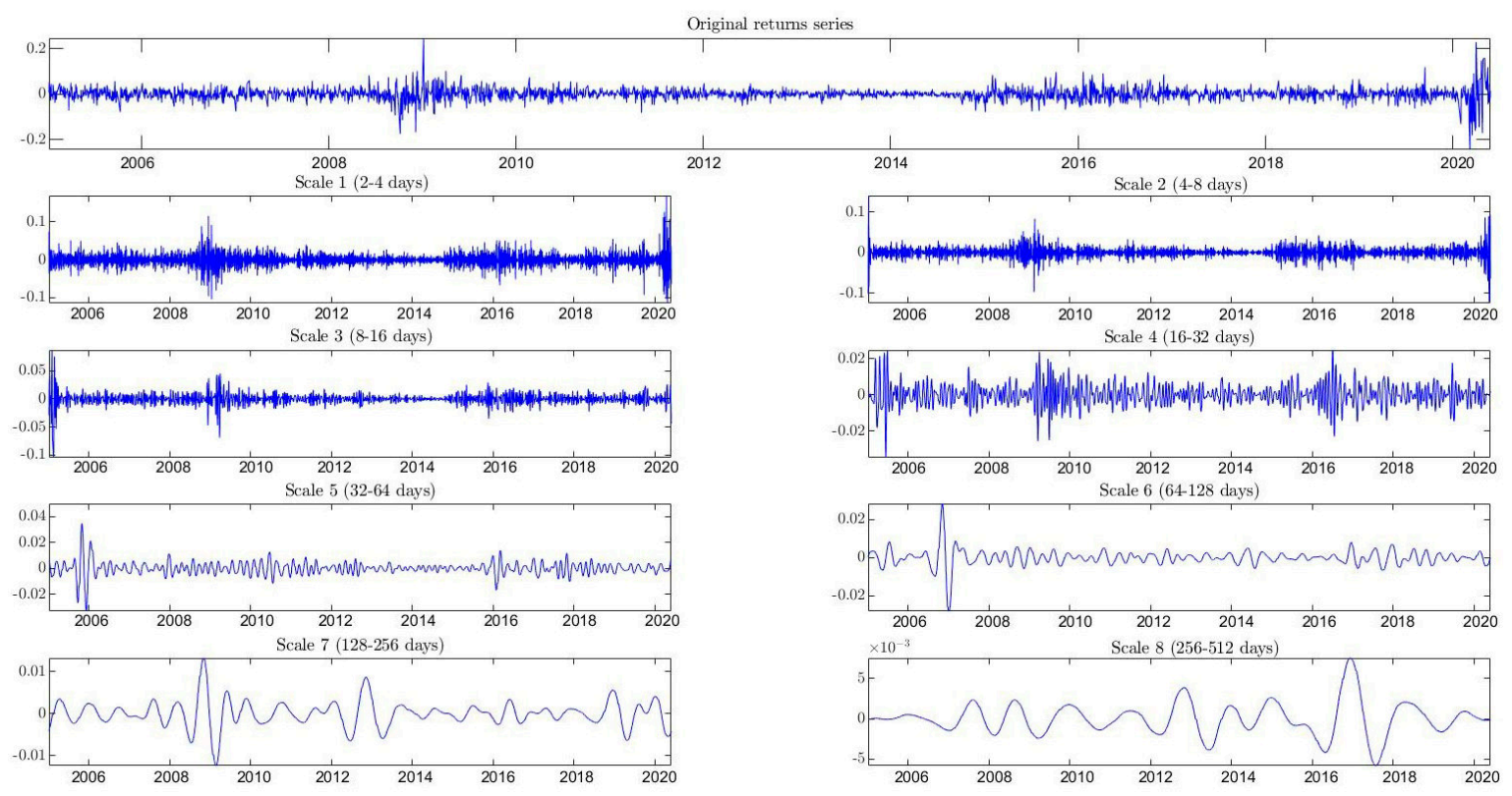

Figure 2. Maximum overlapping discrete wavelet transformation (MODWT) for Brent spot price. 


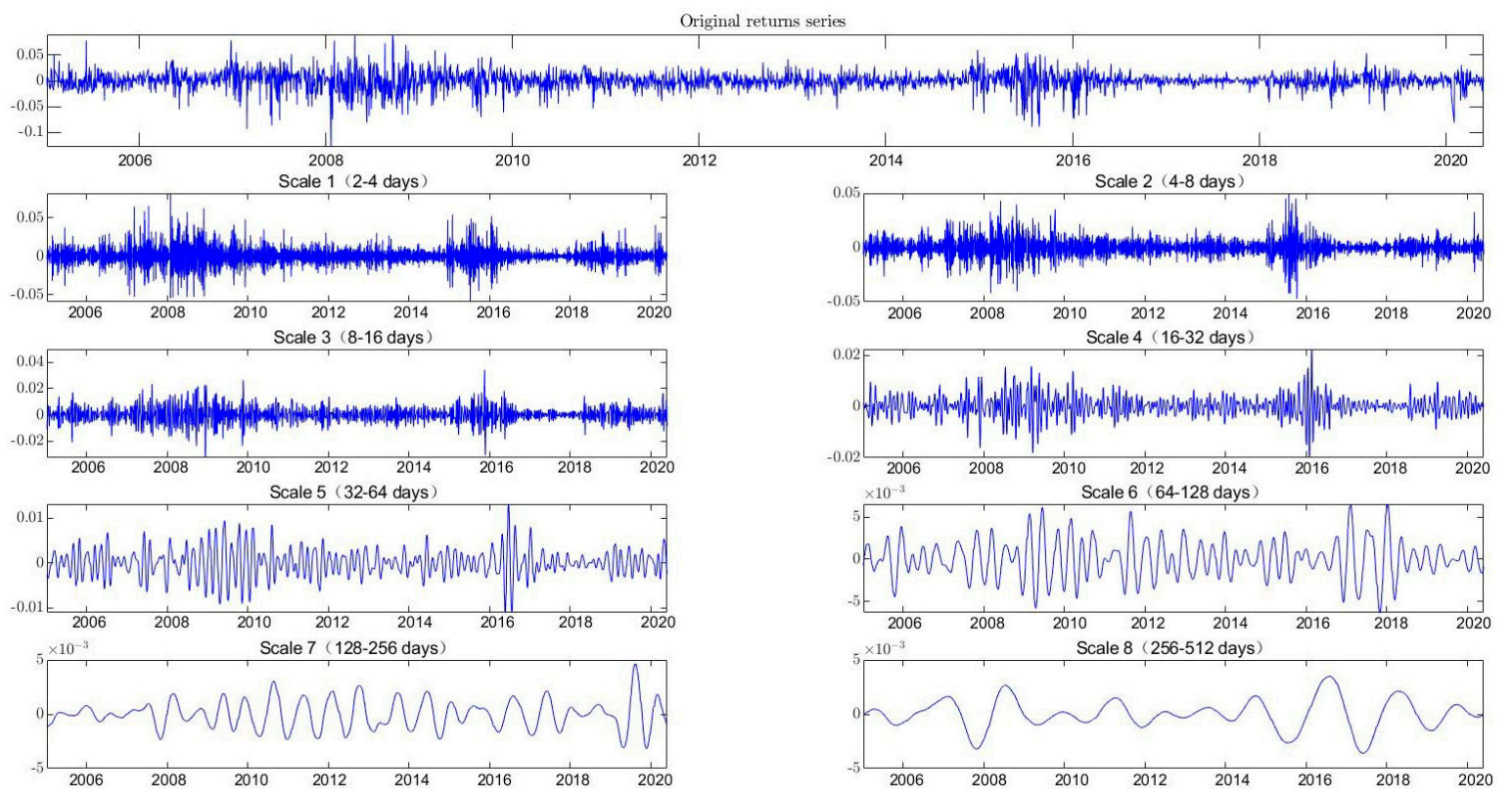

Figure 3. MODWT for the Shanghai Composite Index (SSEC).

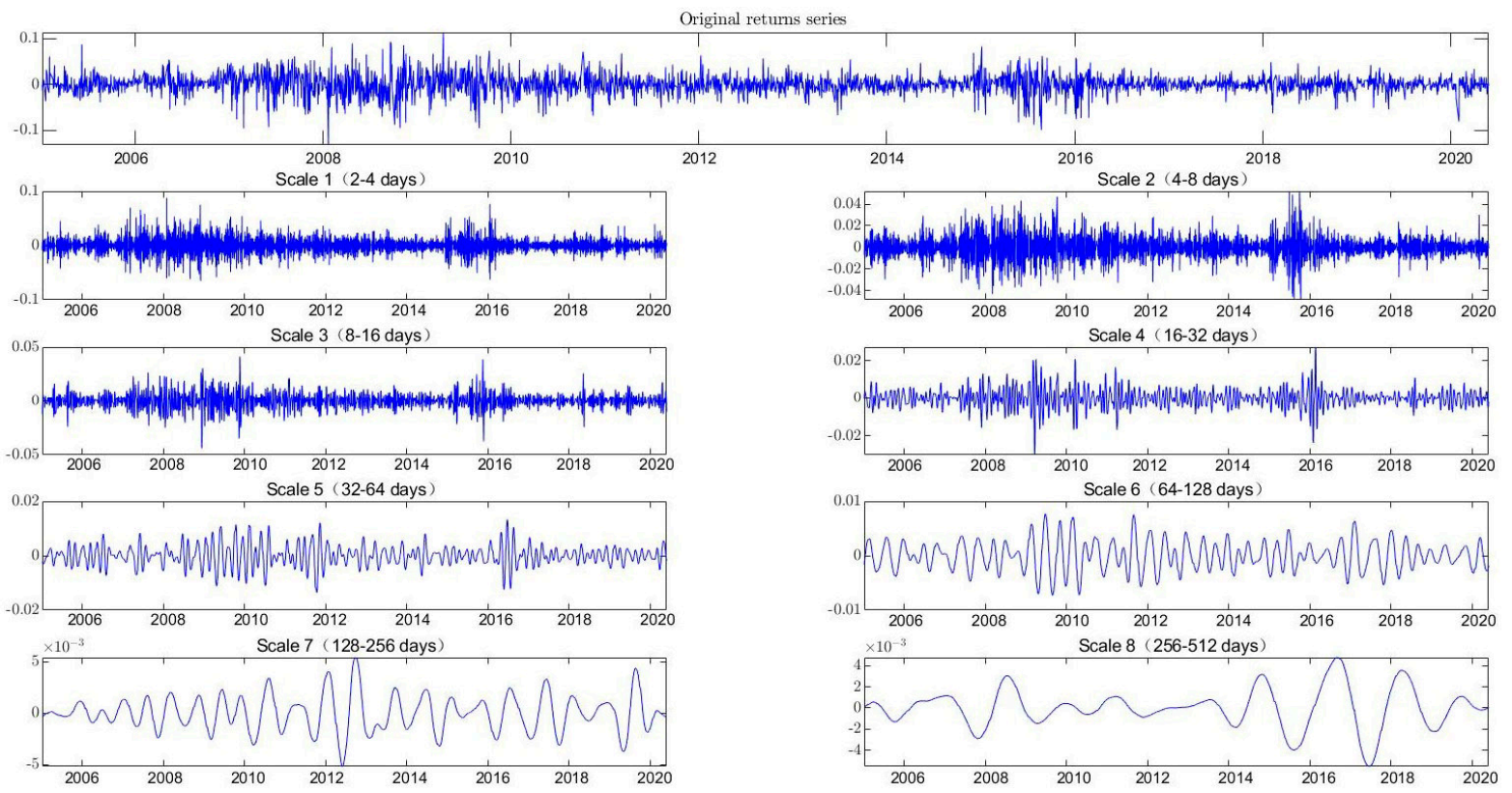

Figure 4. MODWT for CSI-energy (CSIE).

4.2.2. Multi-Time scale Correlation Analysis between Spot Brent Crude Oil and the Stock Index

The correlations among different variables were analyzed according to MODWT (Table 2). First, Brent spot crude oil is positively correlated with the stock indexes under all scales, except for Scale 6, and the correlation coefficients are smaller than $50 \%$. Second, the strongest correlation is observed between Brent spot crude oil and CSI-energy under all scales, except for Scale 6. Under Scale 1, the strongest correlation occurs between the Brent spot crude oil and CSI-consumption. Second, the correlation degree between Brent spot crude oil and the Shanghai Composite Index ranks second in the corresponding time scales, except for Scales 5 and 8, an outcome which reflects the metal attributes of crude oil. Finally, CSI-medicine, CSI-finance, and CSI-public use shows relatively low correlation with Brent spot crude oil, but they are closely related with the corresponding industrial development characteristics [7]. 
Table 2. Multi-scale correlation analysis between with Brent spot price and the stock indexes.

\begin{tabular}{|c|c|c|c|c|c|c|c|c|c|}
\hline & \multicolumn{3}{|c|}{ Original Returns Series } & \multicolumn{3}{|c|}{ Scale 1 (2-4 days) } & \multicolumn{3}{|c|}{ Scale 2 (4-8 days) } \\
\hline & Pearson & Kendall & Spearman & Pearson & Kendall & Spearman & Pearson & Kendall & Spearman \\
\hline SSEC & 12.58 & 7.41 & 10.86 & 8.04 & 4.73 & 7.00 & 16.17 & 8.72 & 12.90 \\
\hline CSIE & 14.79 & 8.74 & 12.91 & 6.96 & 4.08 & 6.03 & 18.92 & 11.92 & 17.55 \\
\hline CSIMA & 12.29 & 6.90 & 10.17 & 7.12 & 4.13 & 6.12 & 15.68 & 8.79 & 13.04 \\
\hline CSII & 10.96 & 6.00 & 8.85 & 7.98 & 4.65 & 6.89 & 12.76 & 6.46 & 9.58 \\
\hline CSIO & 10.75 & 4.84 & 7.17 & 7.76 & 3.72 & 5.52 & 12.08 & 6.04 & 8.95 \\
\hline CSIC & 10.11 & 4.81 & 7.14 & 9.31 & 5.36 & 7.92 & 9.27 & 4.25 & 6.33 \\
\hline CSIME & 8.20 & 3.85 & 5.71 & 7.37 & 4.76 & 7.06 & 7.61 & 2.91 & 4.31 \\
\hline CSIF & 9.89 & 5.66 & 8.31 & 6.11 & 3.47 & 5.14 & 14.08 & 7.93 & 11.75 \\
\hline CSIIN & 10.98 & 4.99 & 7.37 & 7.32 & 3.81 & 5.59 & 12.41 & 5.60 & 8.28 \\
\hline CSIT & 11.22 & 5.04 & 7.48 & 6.57 & 3.37 & 4.99 & 13.80 & 6.04 & 8.92 \\
\hline \multirow[t]{2}{*}{ CSIPU } & 8.82 & 5.26 & 7.77 & 6.70 & 4.31 & 6.42 & 10.33 & 5.54 & 8.23 \\
\hline & \multicolumn{3}{|c|}{ Scale 3 (8-16 days) } & \multicolumn{3}{|c|}{ Scale 4 (16-32 days) } & \multicolumn{3}{|c|}{ Scale 5 (32-64 days) } \\
\hline & Pearson & Kendall & Spearman & Pearson & Kendall & Spearman & Pearson & Kendall & Spearman \\
\hline SSEC & 16.67 & 10.38 & 15.16 & 23.69 & 16.03 & 23.47 & 13.14 & 10.52 & 15.28 \\
\hline CSIE & 25.50 & 16.63 & 24.38 & 29.40 & 18.59 & 27.32 & 15.82 & 15.57 & 22.86 \\
\hline CSIMA & 15.63 & 10.49 & 15.50 & 26.24 & 18.65 & 27.40 & 14.72 & 12.17 & 17.85 \\
\hline CSII & 12.95 & 9.06 & 13.35 & 19.81 & 14.60 & 21.40 & 14.49 & 11.01 & 16.22 \\
\hline CSIO & 11.37 & 8.12 & 12.00 & 18.69 & 12.77 & 18.67 & 14.16 & 9.26 & 13.54 \\
\hline CSIC & 8.47 & 5.38 & 8.01 & 20.45 & 11.75 & 17.33 & 11.21 & 8.76 & 12.90 \\
\hline CSIME & 8.55 & 5.62 & 8.38 & 14.79 & 10.47 & 15.35 & 8.75 & 6.95 & 10.24 \\
\hline CSIF & 11.71 & 7.35 & 10.79 & 16.77 & 11.17 & 16.44 & 13.09 & 10.72 & 15.89 \\
\hline CSIIN & 12.65 & 8.10 & 12.00 & 21.60 & 14.08 & 20.65 & 19.11 & 12.06 & 17.59 \\
\hline CSIT & 18.35 & 10.37 & 15.34 & 24.98 & 14.24 & 21.10 & 11.35 & 6.77 & 10.12 \\
\hline \multirow[t]{2}{*}{ CSIPU } & 13.12 & 9.88 & 14.57 & 14.37 & 10.85 & 16.02 & 7.96 & 5.99 & 8.99 \\
\hline & \multicolumn{3}{|c|}{ Scale 6 (64-128 days) } & \multicolumn{3}{|c|}{ Scale 7 (128-256 days) } & \multicolumn{3}{|c|}{ Scale 8 ( $258-512$ days) } \\
\hline & Pearson & Kendall & Spearman & Pearson & Kendall & Spearman & Pearson & Kendall & Spearman \\
\hline SSEC & 11.17 & 9.18 & 13.52 & 38.39 & 28.28 & 41.51 & 22.34 & 15.11 & 21.47 \\
\hline CSIE & 11.79 & 11.95 & 17.79 & 48.46 & 32.32 & 46.85 & 38.24 & 20.65 & 29.68 \\
\hline CSIMA & 8.83 & 6.97 & 10.34 & 37.62 & 28.15 & 41.04 & 28.09 & 16.39 & 23.91 \\
\hline CSII & 6.60 & 4.99 & 7.42 & 32.05 & 25.10 & 36.80 & 16.40 & 11.82 & 16.89 \\
\hline CSIO & 16.23 & 6.43 & 9.56 & 37.71 & 26.20 & 38.27 & 25.93 & 17.21 & 24.65 \\
\hline CSIC & 0.88 & 0.21 & 0.57 & 31.56 & 21.13 & 30.97 & 42.03 & 30.41 & 43.49 \\
\hline CSIME & -3.16 & 0.91 & 1.45 & 24.56 & 15.56 & 23.02 & 19.91 & 16.59 & 22.51 \\
\hline CSIF & 11.14 & 10.23 & 15.31 & 22.89 & 15.83 & 23.49 & 20.09 & 10.69 & 16.37 \\
\hline CSIIN & 16.29 & 6.95 & 10.29 & 26.23 & 19.70 & 28.59 & 15.37 & 8.91 & 12.29 \\
\hline CSIT & 5.51 & 3.06 & 4.75 & 17.91 & 13.23 & 19.27 & 20.86 & 10.59 & 15.53 \\
\hline CSIPU & -1.08 & 1.83 & 2.47 & 23.49 & 15.79 & 23.52 & 8.58 & 8.24 & 11.96 \\
\hline
\end{tabular}

4.3. Multi-Time scale Analysis of the Influences of International Oil Price Fluctuation on the Shanghai Composite Index According to Continuous and Cross Wavelets

\subsubsection{Continuous Wavelet Decomposition of Brent Spot Crude Oil and the Shanghai Composite Index}

The continuous wavelet transform power spectra of Brent spot crude oil and Shanghai Composite Index are shown in Figure 5. The horizontal axis refers to time (year). The left axis refers to the time scale of the fluctuation period (days) and is presented in the integer powers of 2 . The left axis also covers the continuous time scales from 2 days to 1024 days. The right axis expresses the frequency, which, in turn, is negatively correlated with the time scale. The black solid line in Figure 5 denotes the influence cone curve, and the region within the curve is the significance region on the $5 \%$ level, as estimated according to a Monte Carlo simulation. The colors in Figure 5 refer to the fluctuation energy. The warm colors refer to a great energy volume and a higher degree of fluctuation, whereas the cold colors refer to a smaller degree of fluctuation.

Figure 5 indicates that, during 2005-2020, Brent spot crude oil and the Shanghai Composite Index have a middle-scale and low-scale (2-32 days) high-frequency fluctuation significance zone and a high-scale (256-512 days) low-frequency fluctuation significance zone. Both presented more energy changes in the middle and high scales. During 2008-2009 and 2014-2015, the Brent spot crude oil and Shanghai Composite Index presented significant fluctuations in the middle- and low-frequency zones 
within 60 days. From 2008 to 2009, the crude oil market and stock market were strongly impacted by the global financial crisis, which intensified the fluctuation of Brent spot crude oil and the Shanghai Composite Index. During 2014-2015, reduction of the organization of the petroleum exporting countries (OPEC) crude oil production and the global economic slowdown formed a resultant force that generated frequent changes of crude oil prices and induced stock price fluctuation. Consequently, Brent spot crude oil and the Shanghai Composite Index fluctuate significantly. According to the changes of the fluctuation degree, crude oil price is correlated with the Shanghai Composite Index to some extent. The correlation between crude oil price and the Shanghai Composite Index is highlighted more upon impacts of the important event [28,38].
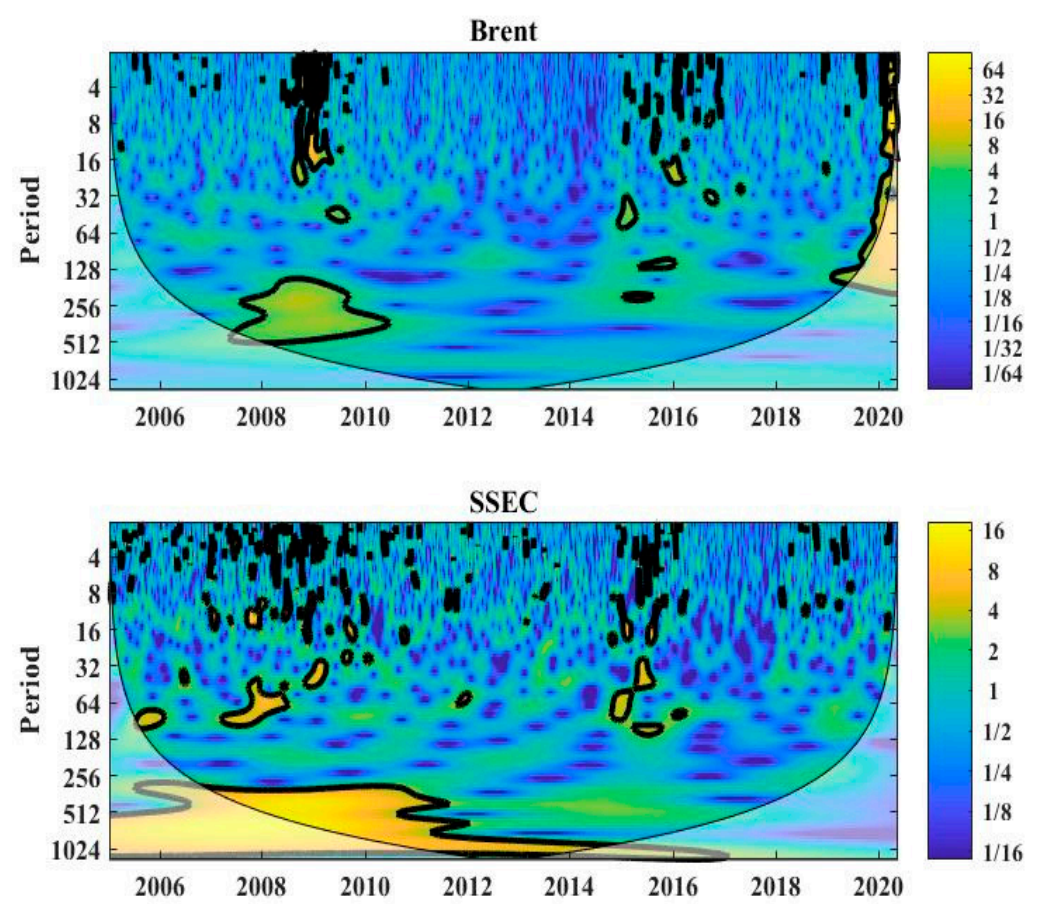

Figure 5. Continuous wavelet transform power spectra of Brent spot price and the Shanghai Composite Index.

Brent spot crude oil showed a high-scale (128-512 days) low-frequency significant fluctuation zone during 2007-2011 and a middle-scale and high-scale (64-256 days) low-frequency significant fluctuation zone during 2015-2016. Occurrences of the two low-frequency significant fluctuation zones indicate that great risk events could influence long-term trend of price fluctuation. Moreover, the self-adjustment of the crude oil market will be reflected in the low-frequency fluctuation zone [7]. In addition, with the COVID-19 epidemic outbreak and the negative price of crude oil futures, Brent spot crude oil presented a significant fluctuation zone that crosses the low, middle, and high time scales (2-256 days), thereby indicating that changes of the economic situations intensify the price fluctuation of a crude oil market. Unlike Brent spot crude oil, the Shanghai Composite Index had a high-scale (256-1024 days) low-frequency significant fluctuation zone at approximately 800 days during 2005-2017. This outcome was related with reform in the crude oil pricing mechanism, financial reform, and increasing openness of finance [39,40].

4.3.2. Multi-Time scale Leading-Lag Relation Analysis between Brent Spot Crude Oil and the Shanghai Composite Index

The cross wavelet power spectra of Brent spot crude oil and the Shanghai Composite Index are shown in Figure 6. The horizontal axis refers to time. The left axis means the time scale of the fluctuation period and the right axis is frequency. A warm color reflects higher energy and the bigger variance under the corresponding time-frequency domain, thereby leading to a higher fluctuation degree. The black arrow refers to the phase relation of the fluctuation between two time series variables. Similar with the continuous wavelet, the mutual influences between Brent spot crude oil and the 
Shanghai Composite Index change with time and frequency. The correlation between Brent spot crude oil and the Shanghai Composite Index is relatively stronger in the low-frequency zone, but it is relatively weak in the high-frequency zone.

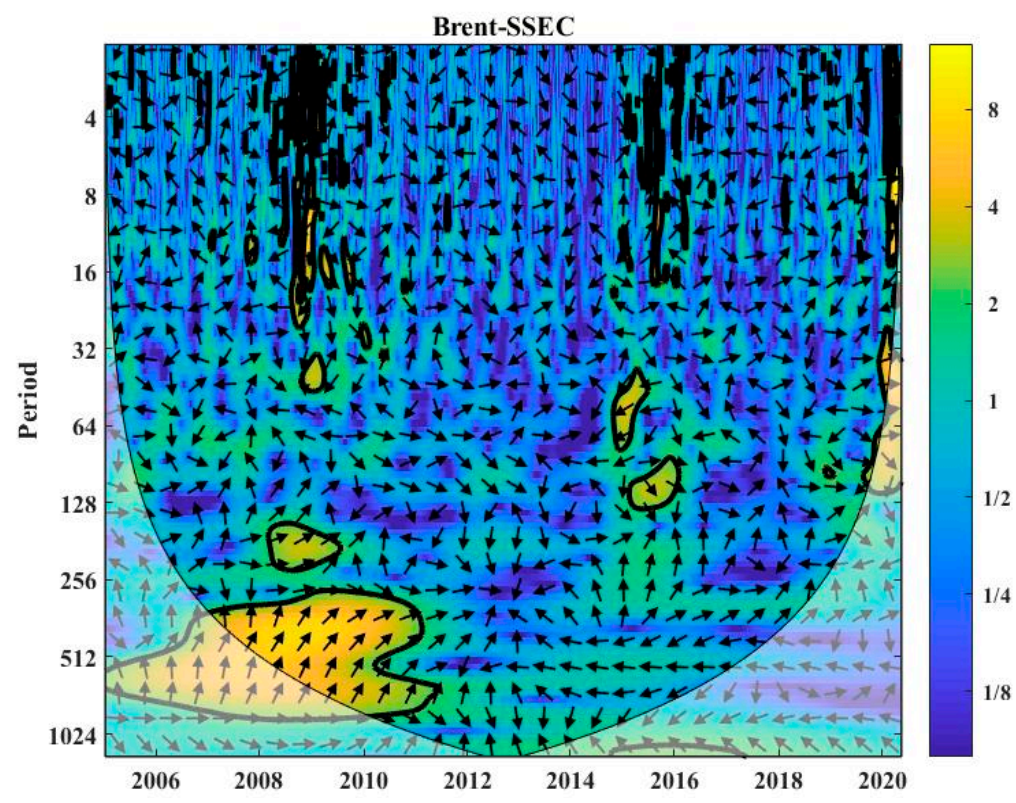

Figure 6. Cross wavelet power frequency spectra of Brent spot price and the Shanghai Composite Index.

First, relatively high cross wavelet power occurs in low-frequency middle- and high-scale zones from 2005 to 2011, 2014 to 2015, and 2019 to 2020. Specifically, the said wavelet power mainly reflects a high-scale (128-256 days) homonymous significant fluctuation zone from 2005 to 2011. A range of 128-256 days of significant fluctuation zone occurred during the international financial crisis, from 2008 to 2009. The arrow mainly indicates the right and the upward directions. This outcome indicates that the changes of Brent spot crude oil are earlier than those of the Shanghai Composite Index. In other words, the dynamic correlation between Brent spot crude oil and the Shanghai Composite Index in the middle and high scales is enhanced upon the impacts of the global financial and European debt crises [39].

Second, the middle-scale (32-128 days) low-frequency reverse significant fluctuation zone took the dominant role during 2014-2015. The arrow of the middle-scale significant zone points left and downward, whereas the arrow of the high-scale significant zone points right and downward. Therefore, the changes of the Brent spot crude oil are earlier than those of the Shanghai Composite Index in the middle scale, while the opposite is observed in the high scale. On the one hand, phase changes suggest that phases of Brent spot crude oil and the Shanghai Composite Index have uneven distributions on different time scales. On the other hand, China's stock markets, which represent an important importer of crude oil and the second largest global economic entity, can exert relatively strong long-term influences on the international crude oil market [40].

Finally, a middle-scale (32-128 days) low-frequency reverse significant fluctuation zone occurs from 2019 to 2020. The arrow direction changes from the right and upper places to the right and lower places, thereby indicating that the relationship between Brent spot crude oil and the Shanghai Composite Index is changing dynamically. Initially, changes of Brent spot crude oil were earlier than those of the Shanghai Composite Index (32-64 days), but changes of the Shanghai Composite Index subsequently became earlier than those of Brent spot crude oil (64-128 days). This outcome was related to the impacts of important events, such as the COVID-19 outbreak, the breakdown of negotiation with crude oil exporters, four stock meltdowns of the United States, and the negative price of crude oil futures. In addition, the changing arrow direction in the rest study periods imply that the distributions of Brent spot crude oil and the Shanghai Composite Index on different time scales are uneven. The above analysis verifies Hypothesis 2. 
4.3.3. Multi-Resolution Correlation Analysis between Brent Spot Crude Oil and the Shanghai Composite Index

The wavelet coherent frequency spectra of Brent spot crude oil and the Shanghai Composite Index are shown in Figure 7. Colors reflect the degree of fluctuation correlation. If a warm color occurs and the correlation coefficient is closer to 1 , the degree of fluctuation correlation is higher. The black arrow refers to the relative phase difference. In the range of $[-\Pi / 2, \Pi / 2]$, two time series make positively correlated homonymous movement; otherwise, the two-time series make negatively correlated reverse movement.

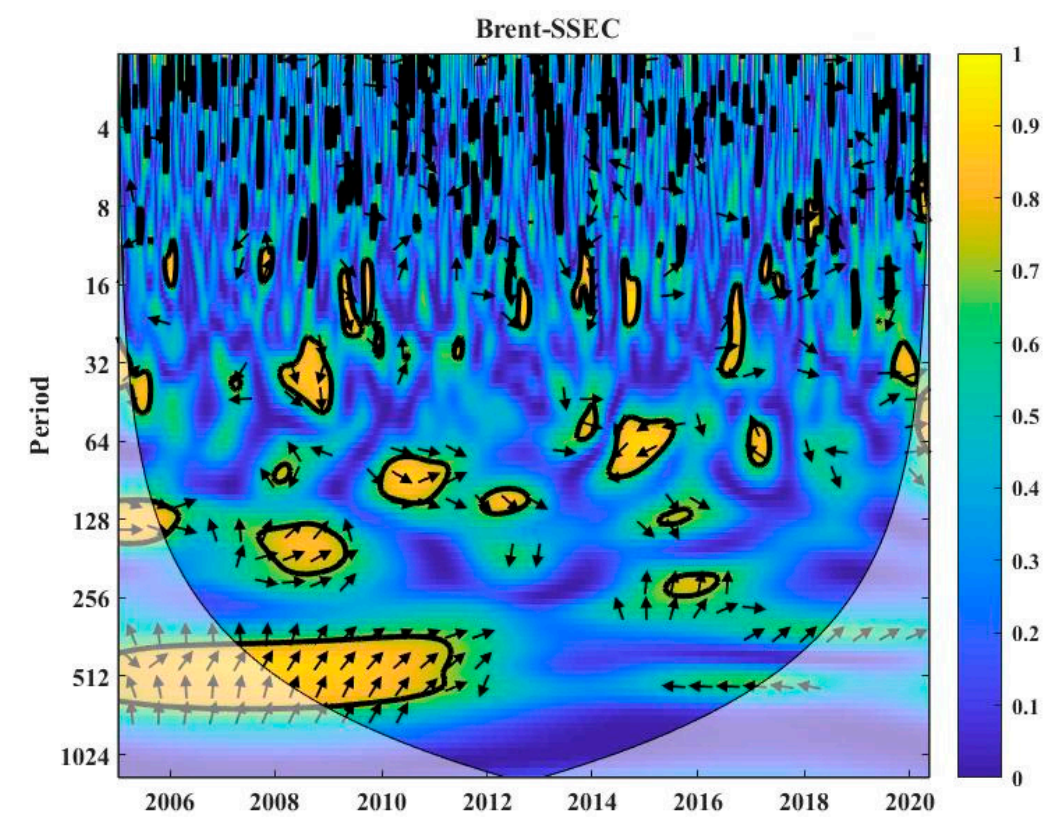

Figure 7. Wavelet coherent frequency spectra of Brent spot price and the Shanghai Composite Index.

Unlike the cross wavelet transform, the high-correlation significance zones of the wavelet coherence between Brent spot crude oil and the Shanghai Composite Index distribute uniformly from 2005 to 2020. First, the phase changes of Brent spot crude oil and the Shanghai Composite Index in the low-scale zone ( $<16$ days) were frequent during 2005-2020. Second, the phase difference between Brent spot crude oil and the Shanghai Composite Index in the middle-scale (32-128 days) high-correlation significance zone mainly concentrates between $-\Pi / 2$ and 0 during 2005-2013. The direction chiefly focuses rightward and downward. This outcome indicates that the changes of the Shanghai Composite Index were earlier than those of Brent spot crude oil, which were correlated with reform in China's stock markets and the crude oil pricing mechanism [23]. In the high-scale (128-2014 days) high-correlation significant fluctuation zone, phase difference concentrates within 0 and $\Pi / 2$. In particular, directions are mainly rightward and upward in approximately 300 days of the high-scale (256-1024 days) significance zone during 2005-2011. This result implies that changes of Brent spot crude oil are earlier than those of the Shanghai Composite Index. This outcome also highlights the financial attribute of crude oil and increased demands of China for crude oil, as well as the continuously strengthening leading role of crude oil market changes in China's stock markets $[6,28]$. In addition, the phase difference between Brent spot crude oil and China's stock markets presented significantly negative correlations in the middle scale (32-128 days) high-correlation significance zone during 2014-2015, with a right downward direction. This reveals that China is a great demander, and changes of China's stock markets can influence the crude oil market and induce fluctuation of crude oil market price [26]. The above analysis verifies Hypothesis 2. 
4.4. Spillover Effect Analysis of International Oil Price Fluctuation on the Stock Index of China Securities Industry According to a Time-Varying t-Copula Model

By using Brent spot crude oil and the stock index of China Securities Industry as analysis objects, the impacts and spillover effect of international oil price fluctuation on the stock index of China Securities Industry were explored by a time-varying t-Copula model based on the multi-time scale yield sequence of MODWT. For pertinent empirical research results, Scales 1, 5, and 8 were chosen as representatives of short-term, mid-term, and long-term fluctuations, respectively. Fluctuation periods corresponding to the three-time scales were 2-4, 32-64, and 256-512 days. These periods can reflect the daily, monthly, and annual spillover effects of oil price fluctuation on the industrial stock index.

4.4.1. Marginal Distribution Estimations of Brent Spot Crude Oil and the Stock Index of China Securities Industry

According to the principle of minimum AIC and SC, as well as the maximum log-likelihood function, and by combining the sharp peak and tails of the financial time series, the marginal distributions of Brent spot crude oil and the stock index of China Securities Industry were estimated with the ARMA(1,0)-EGARCH(1,1) model. For simplification, the marginal distribution estimation of the original yield sequence is introduced in the present section, and the results are listed in Table 3. For the conditional mean equation, only the autoregression coefficient (AR(1)) of CSI-material, CSI-industry, CSI-consumption, CSI-medicine, and CSI-finance passed the significance test, thereby indicating that changes of the current yield of five industrials stocks are readily and significantly influenced by early changes. Second, the AR(1) of Brent spot crude oil and the rest of the five industries failed in the significance test. Thus, early change information of Brent spot crude oil cannot be reflected well as the current yield. Therefore, predicting the variation trend of their yield rates is relatively difficult.

For the conditional fluctuation equation, the coefficient of hysteresis square residue $\mathrm{ARCH}$ and coefficient of the fluctuating hysteresis variance GARCH passed the $t$-test under the $1 \%$ confidence level, thereby indicating that all yield sequences have significant ARCH and GARCH effects. Therefore, the fluctuations of all variables have memories for both Brent spot crude oil and industrial stock index. In other words, the current price fluctuation might significantly influence the price fluctuation in the late stage. For the leverage, the coefficients of all yield sequences, except for Brent spot crude oil and CSI-energy, failed in the significance test. Thus, the conditional fluctuation of these yield sequences is asymmetric. The coefficients of the degree of freedom (DOF) pass the $t$-test under the $1 \%$ confidence level and thus suggests that all yield sequences have thick tails. Consequently, implementing joint tail distribution and synergic movement analysis is possible. Moreover, the residual sequence of all variables shows no evident autocorrelation and heteroscedasticity features, an outcome which implies that the marginal distribution estimation model is stable. 
Table 3. Marginal distribution estimation results of Brent spot price and stock indexes of China Securities Industry.

\begin{tabular}{|c|c|c|c|c|c|c|c|c|c|c|c|}
\hline & Brent & CSIE & CSIMA & CSII & CSIO & CSIC & CSIME & CSIF & CSIIN & CSIT & CSIPU \\
\hline \multicolumn{12}{|c|}{ Mean equation estimates } \\
\hline Const. (\%) & $\begin{array}{c}0.013 \\
(0.000)\end{array}$ & $\begin{array}{c}0.020 \\
(0.000)\end{array}$ & $\begin{array}{c}0.057^{* *} \\
(0.000)\end{array}$ & $\begin{array}{c}0.051 \text { ** } \\
(0.000)\end{array}$ & $\begin{array}{c}0.052 * * \\
(0.000)\end{array}$ & $\begin{array}{c}0.021 \\
(0.000)\end{array}$ & $\begin{array}{c}0.017 \\
(0.000)\end{array}$ & $\begin{array}{l}-0.020 \\
(0.000)\end{array}$ & $\begin{array}{c}0.058^{* *} \\
(0.000)\end{array}$ & $\begin{array}{c}0.065^{* *} \\
(0.000)\end{array}$ & $\begin{array}{c}0.007 \\
(0.006)\end{array}$ \\
\hline $\mathrm{AR}(1)$ & $\begin{array}{c}0.021 \\
(0.016)\end{array}$ & $\begin{array}{l}-0.002 \\
(0.016)\end{array}$ & $\begin{array}{l}0.028^{*} \\
(0.016)\end{array}$ & $\begin{array}{l}0.027^{*} \\
(0.016)\end{array}$ & $\begin{array}{l}0.013 \\
(0.016)\end{array}$ & $\begin{array}{l}0.028^{*} \\
(0.017)\end{array}$ & $\begin{array}{c}0.044^{* * *} \\
(0.017)\end{array}$ & $\begin{array}{c}-0.029 \text { * } \\
(0.016)\end{array}$ & $\begin{array}{c}0.019 \\
(0.017)\end{array}$ & $\begin{array}{l}-0.010 \\
(0.016)\end{array}$ & $\begin{array}{l}-0.006 \\
(0.016)\end{array}$ \\
\hline \multicolumn{12}{|c|}{ GARCH process estimates } \\
\hline Const. $(\Omega)$ & $\begin{array}{c}-0.036^{* *} \\
(0.015)\end{array}$ & $\begin{array}{c}-0.042 * * \\
(0.017)\end{array}$ & $\begin{array}{c}-0.072^{* * *} \\
(0.023)\end{array}$ & $\begin{array}{c}-0.071^{* * * *} \\
(0.022\end{array}$ & $\begin{array}{c}-0.079 * * * \\
(0.024)\end{array}$ & $\begin{array}{c}-0.123 * * * \\
(0.033)\end{array}$ & $\begin{array}{c}-0.060 * * * \\
(0.020)\end{array}$ & $\begin{array}{c}-0.031 \text { ** } \\
(0.015)\end{array}$ & $\begin{array}{c}-0.067^{* * *} \\
(0.023)\end{array}$ & $\begin{array}{c}-0.070^{* * *} \\
(0.024)\end{array}$ & $\begin{array}{c}-0.042^{* *} \\
(0.016)\end{array}$ \\
\hline GARCH $(\beta)$ & $\begin{array}{c}0.995^{* * *} \\
(0.002)\end{array}$ & $\begin{array}{c}0.995^{* * *} \\
(0.002)\end{array}$ & $\begin{array}{c}0.991^{* * *} \\
(0.003)\end{array}$ & $\begin{array}{c}0.991^{* * *} \\
(0.003)\end{array}$ & $\begin{array}{c}0.990 * * * \\
(0.003)\end{array}$ & $\begin{array}{c}0.985 * * * \\
(0.004)\end{array}$ & $\begin{array}{c}0.993 * * * \\
(0.002)\end{array}$ & $\begin{array}{c}0.996 * * * \\
(0.002)\end{array}$ & $\begin{array}{c}0.991^{* * *} \\
(0.003)\end{array}$ & $\begin{array}{c}0.991 * * * \\
(0.003)\end{array}$ & $\begin{array}{c}0.995^{* * *} \\
(0.002)\end{array}$ \\
\hline $\mathrm{ARCH}(\alpha)$ & $\begin{array}{c}0.095^{* * *} \\
(0.012)\end{array}$ & $\begin{array}{c}0.118^{* * * *} \\
(0.014)\end{array}$ & $\begin{array}{c}0.141^{* * * *} \\
(0.016)\end{array}$ & $\begin{array}{c}0.143^{* * *} \\
(0.016)\end{array}$ & $\begin{array}{c}0.154^{* * *} \\
(0.017)\end{array}$ & $\begin{array}{c}0.167^{* * *} \\
(0.018)\end{array}$ & $\begin{array}{c}0.145^{* * *} \\
(0.016)\end{array}$ & $\begin{array}{c}0.117^{* * *} \\
(0.014)\end{array}$ & $\begin{array}{c}0.140^{* * *} \\
(0.016)\end{array}$ & $\begin{array}{c}0.146^{* * *} \\
(0.016)\end{array}$ & $\begin{array}{c}0.141^{* * *} \\
(0.015)\end{array}$ \\
\hline Leverage $(\theta)$ & $\begin{array}{c}-0.049^{* * *} \\
(0.007)\end{array}$ & $\begin{array}{l}0.015^{*} \\
(0.008)\end{array}$ & $\begin{array}{l}-0.003 \\
(0.008)\end{array}$ & $\begin{array}{l}-0.007 \\
(0.009)\end{array}$ & $\begin{array}{l}-0.007 \\
(0.009)\end{array}$ & $\begin{array}{l}-0.005 \\
(0.010)\end{array}$ & $\begin{array}{c}0.003 \\
(0.009)\end{array}$ & $\begin{array}{c}0.004 \\
(0.008)\end{array}$ & $\begin{array}{l}-0.003 \\
(0.009)\end{array}$ & $\begin{array}{c}0.009 \\
(0.009)\end{array}$ & $\begin{array}{c}0.012 \\
(0.009)\end{array}$ \\
\hline DOF & $\begin{array}{c}5.791^{* * * *} \\
(0.543)\end{array}$ & $\begin{array}{l}4.711^{* * *} \\
(0.435)\end{array}$ & $\begin{array}{c}5.142 * * * \\
(0.520)\end{array}$ & $\begin{array}{c}5.156^{* * *} \\
(0.449)\end{array}$ & $\begin{array}{c}5.647^{* * * *} \\
(0.540)\end{array}$ & $\begin{array}{c}6.332 * * * \\
(0.695)\end{array}$ & $\begin{array}{c}7.229 * * * \\
(0.814)\end{array}$ & $\begin{array}{c}4.437^{* * *} \\
(0.388)\end{array}$ & $\begin{array}{c}6.863^{* * *} \\
0.743\end{array}$ & $\begin{array}{c}5.083^{* * *} \\
(0.485)\end{array}$ & $\begin{array}{c}5.357^{* * * *} \\
(0.451)\end{array}$ \\
\hline $\log (\mathrm{L})$ & 9011.780 & 9434.185 & 9418.582 & 9739.258 & 9690.367 & 9718.485 & 9703.576 & 9696.404 & 8958.648 & 9090.397 & 9011.780 \\
\hline AIC & $-18,009.561$ & $-18,854.371$ & $-18,823.164$ & $-19,464.516$ & $-19,366.734$ & $-19,422.971$ & $-19,393.152$ & $-19,378.808$ & $-17,903.297$ & $-18,166.794$ & $-18,009.561$ \\
\hline $\mathrm{BIC}$ & $-17,966.250$ & $-18,811.060$ & $-18,779.853$ & $-19,421.205$ & $-19,323.423$ & $-19,379.660$ & $-19,349.841$ & $-19,335.497$ & $-17,859.986$ & $-18,123.483$ & $-17,966.250$ \\
\hline $\mathrm{Q}(15)$ & 19.438 & 28.676 & 36.803 & 36.252 & 25.416 & 22.204 & 25.990 & 36.290 & 12.952 & 23.010 & 19.438 \\
\hline $\mathrm{Q}^{2}(15)$ & 17.508 & 10.457 & 14.822 & 12.981 & 13.416 & 17.245 & 10.649 & 11.939 & 12.903 & 25.112 & 17.508 \\
\hline $\mathrm{ARCH}(15)$ & 18.539 & 10.582 & 14.849 & 12.917 & 13.046 & 17.879 & 10.661 & 12.605 & 12.845 & 25.044 & 18.539 \\
\hline
\end{tabular}

Notes: The table presents the marginal distribution estimation results, and standard errors are presented in parenthesis. Const. indicates constant term. AR indicates autoregressive. BIC indicates Bayesian information criterion $\mathrm{Q}(15), \mathrm{Q}^{2}(15)$, and $\mathrm{ARCH}(15)$ are empirical statistics of Ljung-Box test for autocorrelation with 15 lags in residuals and squared residuals, and the ARCH effects test by Engle(1982) with 15 lags, respectively. ${ }^{*}, * *$, and ${ }^{* * *}$ represent statistical significance at the $10 \%$ level, at the $5 \%$ level, and at the $1 \%$ level, respectively. 
4.4.2. Multi-Time scale Spillover Effect of Brent Spot Crude Stock and Stock Index of China Securities Industry According to a Time-Varying t-Copula Model

After the best marginal distribution is determined, the dynamic dependence between Brent spot crude oil and the stock index of China Securities Industry was analyzed by using a time-varying $\mathrm{t}$-Copula model. Estimation results of the $\mathrm{t}$-Copula model of the original yield, short-term fluctuation, middle-term fluctuation, and long-term fluctuation sequences of the Brent spot crude oil and the stock index of China Securities Industry are listed in Table 4 and Appendix A Tables A2-A4. For better contrast analysis, the estimation results of static $\mathrm{t}$-Copula are also presented in the tables.

Table 4 indicates that, first, the AIC values of most time-varying t-Copula models are smaller than those in the static model, and the log-likelihood value is higher than that of the static model. Thus, the time-varying t-Copula model is superior to its static counterpart. The fitting degree of the time-varying model is higher. Second, the estimated values of all parameters $\rho$ in the static t-Copula model are positive and significant under the $1 \%$ level. The fluctuation range of the spillover effect of Brent spot crude oil to the industrial stock index is between 0.057 (CSI-medicine) and 0.132 (CSI-energy). Third, the estimated values of most parameters $\rho$ and $\beta$ in the time-varying t-Copula model are positive and pass the $t$-test under the $1 \%$ confidence level. The numerical value of $\rho$ is between 0.069 (CSI-medicine) and 0.142 (CSI-energy). In the dynamic model, the estimated influences of Brent spot crude oil on different industrial stock indexes are higher than the estimated value in the static model. Most $\beta$ values are close to 1 and suggest that the influences of Brent spot crude oil on the stock index of China Securities Industry have strong continuity [6,41]. Moreover, the DOF in the time-varying t-Copula model is significant under the $1 \%$ level except for CSI-information, and the numerical value is relatively small. This outcome indicates strong synergic effect and tail dependence between Brent spot crude oil and the stock index of China Securities Industry. Finally, in both static and dynamic t-Copula models, CSI-energy, CSI-material, and CSI-industry are three industries influenced mostly by Brent spot crude oil. This result indicates that, as the basic energy and raw material, the price fluctuation of crude oil can directly cause impacts to related upstream and downstream industries directly [14,42].

As the $\mathrm{t}$-Copula model can describe the tail dependence correlation between two time series variables well, the tail correlation time series diagram between Brent spot crude oil and CSI-energy is drawn (Figure 8). The correlation between Brent spot crude oil and CSI-energy is relatively low (0.132) in the static $\mathrm{t}$-Copula model, but it fluctuates greatly in the time-varying $\mathrm{t}$-Copula model. During the global financial crisis in 2008-2009 and the European debt crisis in 2010-2011, an evident positive correlation occurs between Brent spot crude oil and industrial stock index in the tail. During the financial crisis, the dynamic correlation coefficient was smaller than the static one, but the opposite phenomenon was observed during the European debt crisis. The tail presented significantly negative correlation between Brent spot crude oil and industrial stock index under the impacts of the OPEC reduced yield and the American reform in shale oil. With the global spread of the COVID-19 epidemic in 2020, the dynamic correlation was enhanced significantly. To sum up, the time-varying t-Copula model can better reflect the dynamic correlation and tail dependence between Brent spot crude oil and the industrial stock index [6].

The estimated results of the t-Copula model between Brent spot crude oil and the stock index of China Securities Industry under short-term (Scale 1), middle-term (Scale 5), and long-term fluctuations (Scale 8) are listed from Appendix A Tables A2-A4. In a word, the AIC value of the time-varying $\mathrm{t}$-Copula model is considerably smaller than that of the static model under short-term, middle-term, and long-term fluctuations. Moreover, the log-likelihood value of time-varying t-Copula model is generally higher than that of the static model, thereby indicating that the time-varying t-Copula model can better capture the impacts and spillover effect of international oil price fluctuation on industrial sectors of China under different fluctuation periods or different time scales. 
Table 4. Estimates of t-Copula for original returns series between Brent spot price and the stock indexes of China Securities Industry.

\begin{tabular}{|c|c|c|c|c|c|c|c|c|c|c|}
\hline & CSIE & CSIMA & CSII & CSIO & CSIC & CSIME & CSIF & CSIIN & CSIT & CSIPU \\
\hline \multicolumn{11}{|c|}{ Static Student-t-Copula parameters } \\
\hline$\rho$ & $\begin{array}{l}0.132 \text { *** } \\
(-0.017)\end{array}$ & $\begin{array}{l}0.109 * * * \\
(-0.017)\end{array}$ & $\begin{array}{l}0.093^{* * *} \\
(-0.017)\end{array}$ & $\begin{array}{l}0.073^{* * *} \\
(-0.017)\end{array}$ & $\begin{array}{l}0.073^{* * *} \\
(-0.017)\end{array}$ & $\begin{array}{l}0.057^{* * *} \\
(-0.018)\end{array}$ & $\begin{array}{l}0.086^{* * *} \\
(-0.017)\end{array}$ & $\begin{array}{l}0.076^{* * *} \\
(-0.017)\end{array}$ & $\begin{array}{l}0.071^{* * *} \\
(-0.017)\end{array}$ & $\begin{array}{l}0.082^{* * *} \\
(-0.017)\end{array}$ \\
\hline DOF & $\begin{array}{c}13.657^{* * * *} \\
(3.480)\end{array}$ & $\begin{array}{c}14.737^{* * * *} \\
(4.081)\end{array}$ & $\begin{array}{c}14.982 * * * \\
(4.169)\end{array}$ & $\begin{array}{c}13.910 * * * \\
(3.993)\end{array}$ & $\begin{array}{c}19.167^{* * *} \\
(7.434)\end{array}$ & $\begin{array}{c}12.018 * * * \\
(2.899)\end{array}$ & $\begin{array}{c}11.303 * * * \\
(2.474)\end{array}$ & $\begin{array}{c}15.547^{* * * *} \\
(4.655)\end{array}$ & $\begin{array}{c}12.100 * * * \\
(2.930)\end{array}$ & $\begin{array}{l}15.068 \\
(4.234)\end{array}$ \\
\hline $\log (\mathrm{L})$ & 45.573 & 32.765 & 25.057 & 21.801 & 16.896 & 18.842 & 28.616 & 19.190 & 23.106 & 22.167 \\
\hline AIC & -89.147 & -63.530 & -48.114 & -41.602 & -31.793 & -35.684 & -55.232 & -36.379 & -44.211 & -42.333 \\
\hline \multicolumn{11}{|c|}{ DCC-Student-t-Copula parameters } \\
\hline$\rho$ & $\begin{array}{c}0.142^{* * *} \\
(0.001)\end{array}$ & $\begin{array}{c}0.113^{* * *} \\
(0.001)\end{array}$ & $\begin{array}{c}0.098^{* * *} \\
(0.001)\end{array}$ & $\begin{array}{c}0.089 * * * \\
(0.001)\end{array}$ & $\begin{array}{c}0.083^{* * *} \\
(0.001)\end{array}$ & $\begin{array}{c}0.069 * * * \\
(0.001)\end{array}$ & $\begin{array}{c}0.093^{* * *} \\
(0.001)\end{array}$ & $\begin{array}{c}0.083^{* * *} \\
(0.000)\end{array}$ & $\begin{array}{c}0.087^{* * * *} \\
(0.000)\end{array}$ & $\begin{array}{c}0.089^{* * *} \\
(0.001)\end{array}$ \\
\hline DOF & $\begin{array}{c}14.884^{* * *} \\
(4.017)\end{array}$ & $\begin{array}{c}16.073^{* * * *} \\
(4.495)\end{array}$ & $\begin{array}{c}16.312 * * * \\
(5.146)\end{array}$ & $\begin{array}{c}14.811^{* * * *} \\
(4.668)\end{array}$ & $\begin{array}{c}20.618^{* *} \\
(8.194)\end{array}$ & $\begin{array}{c}12.398^{* * * *} \\
(3.051)\end{array}$ & $\begin{array}{c}11.707^{* * * *} \\
(2.766)\end{array}$ & $\begin{array}{c}16.507 \\
(122.219)\end{array}$ & $\begin{array}{c}12.792 * * * \\
(3.219)\end{array}$ & $\begin{array}{c}15.683^{* * *} \\
(4.700)\end{array}$ \\
\hline$\alpha$ & $\begin{array}{c}0.023 \\
(0.022)\end{array}$ & $\begin{array}{l}0.006^{*} \\
(0.003)\end{array}$ & $\begin{array}{c}0.013^{* *} \\
(0.005)\end{array}$ & $\begin{array}{c}0.013^{* *} \\
(0.006)\end{array}$ & $\begin{array}{l}0.009^{*} \\
(0.004)\end{array}$ & $\begin{array}{l}0.009^{*} \\
(0.006)\end{array}$ & $\begin{array}{c}0.007 \\
(0.005)\end{array}$ & $\begin{array}{c}0.029 \\
(1.561)\end{array}$ & $\begin{array}{c}0.029 \\
(0.025)\end{array}$ & $\begin{array}{c}0.007 \\
(0.009)\end{array}$ \\
\hline$\beta$ & $\begin{array}{c}0.922^{* * *} \\
(0.118)\end{array}$ & $\begin{array}{c}0.990^{* * *} \\
(0.007)\end{array}$ & $\begin{array}{c}0.964^{* * *} \\
(0.021)\end{array}$ & $\begin{array}{c}0.951^{* * *} \\
(0.024)\end{array}$ & $\begin{array}{c}0.964^{* * *} \\
(0.021)\end{array}$ & $\begin{array}{c}0.955^{* * *} \\
(0.032)\end{array}$ & $\begin{array}{c}0.988^{* * *} \\
(0.013)\end{array}$ & $\begin{array}{c}0.000 \\
(50.261)\end{array}$ & $\begin{array}{c}0.017 \\
(0.454)\end{array}$ & $\begin{array}{c}0.987^{* * *} \\
(0.027)\end{array}$ \\
\hline $\log (\mathrm{L})$ & 54.715 & 41.233 & 31.587 & 26.081 & 19.519 & 21.058 & 36.823 & 20.460 & 24.349 & 27.844 \\
\hline AIC & -103.430 & -76.465 & -57.174 & -46.163 & -33.038 & -36.116 & -67.647 & -34.920 & -42.697 & -49.687 \\
\hline
\end{tabular}

Notes: This table reports the estimates of static Student-t-Copula and dynamic conditional correlation (DCC)-Student-t-Copula for original returns series between Brent spot crude oil and the stock index of China Securities Industry. Standard errors are presented in parenthesis. ${ }^{*}, * *$, and ${ }^{* * *}$ represent statistical significance at the $10 \%$ level, at the $5 \%$ level, and at the $1 \%$ level, respectively. $\mathrm{DOF}=$ degree of freedom. 


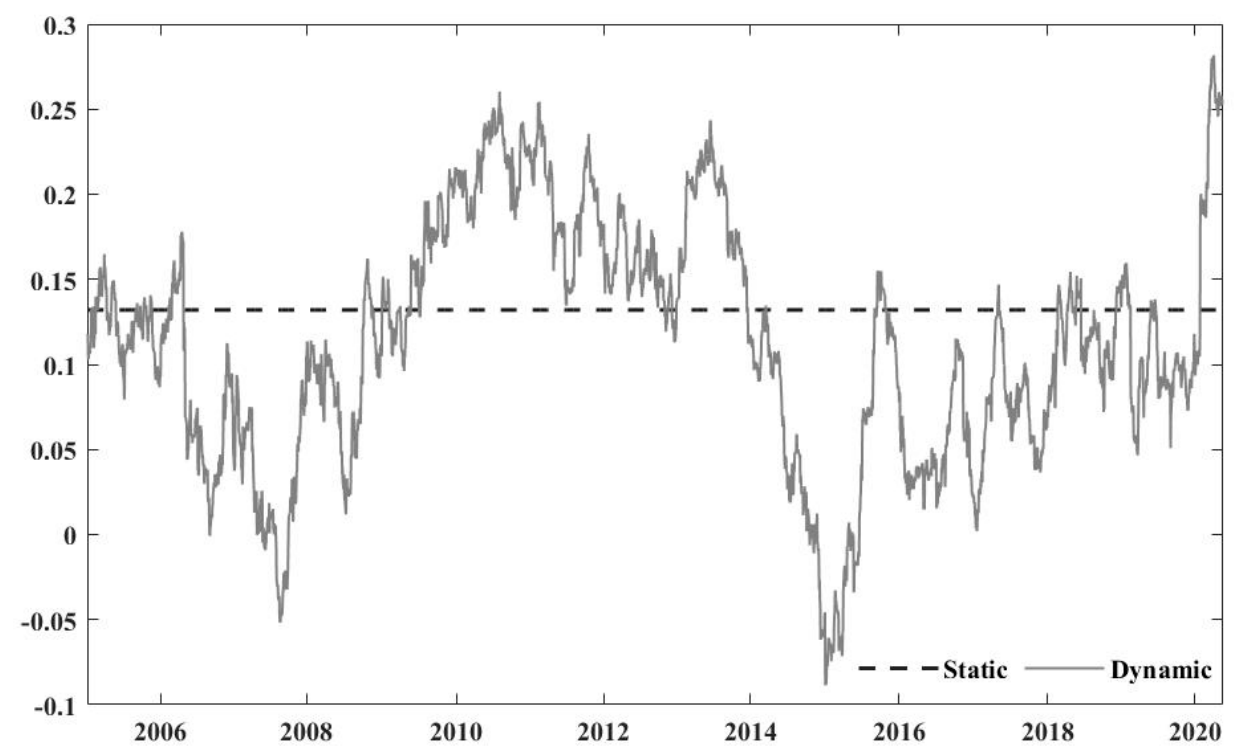

Figure 8. Tail correlation between the Brent spot price and the yield of CSI-energy.

For the estimation results of $\mathrm{t}$-Copula model under short-term fluctuation, the estimation results of all parameters $\rho$ are positive and significant under the $1 \%$ level. In addition to CSI-material, CSI-industry, CSI-optional, and CSI-public use, the value of $\rho$ in the static model is higher than or equal to that in the dynamic model. Moreover, Brent spot crude oil influences CSI-consumption maximally and CSI-communication minimally. The numerical values in the dynamic model are 0.067 and 0.039 , and the numerical values in the static model are 0.070 and 0.042 . This outcome differs from the estimation results of the original benefits to some extent and is closely related with high foreign-trade dependence on China's crude oil market and the incomplete marketization of crude oil pricing. Second, $\beta$ values of only CSI-energy and CSI-material are significant in the dynamic model, and the estimated values are relatively small; thus, relatively low continuity of impacts of oil price changes occur on the stock index of China Securities Industry under short-term fluctuation [8]. Moreover, estimation results of the DOF of nearly $50 \%$ stock indexes are insignificant and suggest a correlation between oil price changes and the stock index of China Securities Industry under short-term fluctuation. In particular, tail dependence is relatively weak.

With respect to the estimation results of the $\mathrm{t}$-Copula model under middle-term fluctuation, similar with short-term fluctuation results, the estimated value of parameter $\rho$ is positive and significant under the $1 \%$ level. The values of parameter $\rho$ in the dynamic and static models are higher than those under short-term fluctuation, thereby indicating that the influences of oil price fluctuation on the stock index of China Securities Industry are enhanced, to some extent, under middle-term fluctuation [41]. CSI-energy achieved maximum $\rho$ values $(0.189,0.215)$ in both static and dynamic models, whereas CSI-communication achieved the minimum $\rho$ value $(0.061)$ in the dynamic model. Furthermore, CSI-public use achieved the minimum $\rho$ value $(0.066)$ in the static model. The variation trend of the rest yield sequence is similar with the short-term fluctuation. Second, all parameters $\beta$ pass the $t$-test significantly in the dynamic model and the numerical values are higher compared to those under short-term fluctuation. This outcome indicates that the continuity of the spillover effect of oil price fluctuation on the stock index of China Securities Industry is increased, to some extent, in the middle-term fluctuation [5]. Finally, DOF estimation results of the rest of industrial stock indexes, in addition to CSI-optional, CSI-finance, and CSI-public use, are significant under the $1 \%$ level and have considerable numerical values. This outcome reveals that the correlation between oil price fluctuation and industrial stock index, especially the tail dependence, is enhanced, to some extent, under middle-term fluctuations.

For the estimation results of the $t$-Copula model under long-term fluctuation, all $\rho$ parameters are positive and significant under the $1 \%$ level, except for CSI-public use, thereby indicating the positive 
spillover effect of oil price fluctuation on the stock index of China Securities Industry. Parameters $\rho$ of CSI-consumption and CSI-energy occupy the first and second columns in the dynamic and static models, thereby indicating that the commodity attribute and financial attribute of crude oil are further highlighted in the long-term variation trend [6]. Second, parameter $\beta$ in the dynamic model of the rest of the variables all pass through the $t$-test significantly except for the CSI-medicine. Moreover, the estimation results of $\beta$ are close to 1 and suggest that the continuity of the spillover effect of international oil price impacts on stock index of China Securities Industry is further enhanced under long-term fluctuation. Finally, the DOF of all industrial stock indexes in the dynamic model is significant under the $1 \%$ level, and the numerical values are relatively large. Thus, the correlation between international oil price changes and the stock index of China Security Industry, especially the tail dependence, is enhanced significantly under long-term fluctuation [43]. The above analysis verifies Hypothesis 3.

\subsection{Robustness Test}

To test the robustness of the above empirical analysis results, the West Texas Intermediate (WTI) crude oil price and Brent crude oil price are international benchmark oil prices with relatively high correlation between them. In this study, WTI spot crude oil was used to replace Brent spot crude oil for secondary wavelet analysis and the estimation of time-varying the $t$-Copula model. Limited by the article length, the cross wavelet coherent frequency spectra between WTI spot crude oil and Shanghai Composite Index (Appendix A Figure A1) and estimation results of the t-Copula model of their original yield sequences (Appendix A Table A5) were only introduced in this work. The research results of wavelet coherence and t-Copula model were similar with those of Brent spot crude oil, thereby indicating that the research conclusions were robust.

\section{Discussions}

According to empirical analysis results, the spillover effect of international oil price fluctuation on China's stock markets is changing dynamically and the spillover effect distribution on different time scales is uneven. This is in line with the findings of other studies $[44,45]$. The spillover effect on different industries is continuous, and tail dependence occurs. On the basis of the above empirical analysis results, further discussions are implemented in the following text.

First, results in Figures 2-4 and Table 2 indicate that the spillover effect of international oil price fluctuation on China's stock markets is changing dynamically under different time scales. The correlation between international oil price fluctuation and China's stock markets is enhanced by the impacts from great risk events. Under different fluctuation periods, impacts on the energy industry are the most obvious, but the consumption industry is affected more in the short run. This outcome is similar with the research conclusions of Ahmed et al. [4] and Huang et al. [27], and the above conclusions verify Hypothesis 1 . This outcome mainly occurs because, on the one hand, the financial attribute and strategic energy position of crude oil are highlighted increasingly, and the integration between the crude oil market and financial market is accelerating continuously [45]. When a market price fluctuates because of impacts from risk events, the price fluctuation of other markets will be induced according to the transmission effect of the price and financial contagion effect [46]. Thus, price correlation and the information spillover between the crude oil market and stock market are strengthened as a result of risk events [47]. On the other hand, crude oil is a basic energy source and the rise of international oil price might incur a higher cost for China's energy industry, consequently inducing stock price fluctuation of the energy industry [48]. Meanwhile, the consumption industry in the short-term is affected by oil price impact because of the existence of import volume of China's crude oil and the viscosity of crude oil price. However, the energy industry is influenced substantially [49].

Second, the results in Figures 2,3 and 5-7 show that the overall spillover effects of international oil price on China's stock markets are uneven on different time scales. In the short run, oil price impact mainly intensifies the fluctuation amplitude of the stock market. In the middle and long run, changes of China's stock markets occur earlier than those of oil price. This outcome echoes the research 
conclusions of Sarwar et al. [28] and Korotin et al. [39], and the above conclusions verify Hypothesis 2. This finding can be interpreted from the following two aspects. On the one hand, given that China has no right speech in international crude oil pricing, China will remain a passive bearer of international oil price fluctuation in the short run. Therefore, the international crude oil market has a relatively evident information spillover effect on China's stock markets in the short run. On the other hand, policies concerning responses of China's financial market to the international crude oil market impacts will be adjusted over time. Moreover, China can influence crude oil demand as the second largest global economic entity, and the long-term information spillover and influencing ability of China's stock markets on international crude oil market will be strengthened. The long-term leading relation between international crude oil market and China's stock markets might change accordingly.

Third, the results in Table 4 and Appendix A Tables A2-A4 and Figure 8 reveal that, under a single time dimension, the influences of oil price fluctuation on different industrial stock indexes are continuous and have tail dependence. Under different fluctuation stages, the spillover effect, in the short run, has relatively low continuity and tail dependence but will be strengthening gradually in the middle and long run. This outcome agrees with the research conclusions of Fang and Egan [6] and Jesus et al. [14], and the above conclusions verify Hypothesis 3. The major reasons for those results are introduced as follows. On the one hand, crude oil is a basic energy and raw material that is closely associated with the production and development of different industries. Besides, foreign-trade dependence of China's crude oil is relatively high. Therefore, internal crude oil price fluctuation might cause the continuity of different industrial developments of China and induce fluctuation of the stock indexes of the stock market. On the other hand, tail dependence between international oil price and the stock index of China Securities Industry is relatively weak in the short run and is determined by development features of various industries and their different response abilities to oil price impacts. In the middle and long run, the variation trend and correlation between international oil price fluctuation and the stock index of China Securities Industry are further enhanced, accompanied with the enhanced continuity and tail dependence of the spillover effect.

\section{Conclusions}

According to comprehensive stock and industrial indexes, the comprehensive effects and time-varying spillover differences of international oil price fluctuation on China's stock markets are measured and analyzed comprehensively from the perspective of multi-time scales, by combining wavelet analysis and the Copula model. This paper finds that, first of all, when it is impacted by major risk events, the linkage between international oil price and China's stock markets will be enhanced; under different volatility periods, the impact on the energy industry has suffered the most, but in the short term, the consumption industry is more affected. Secondly, in the short term, oil price shocks mainly aggravate the stock market volatility, and in the medium and long term, it mainly affects the fluctuation trend. The spillover effect of international oil price on China's stock markets is unevenly distributed in various time scales: Under the medium-term fluctuation, the oil price changes ahead of the changes in China's stock market, while in the long-term, it fluctuations; the latter is ahead of the former. Finally, the impact of oil price fluctuation on the stock index of various industries has persistence and tail correlation in a single time dimension; in different volatility periods, the persistence and tail correlation of spillover effect are low in the short term, and gradually increase in the medium and long term; under the short-term fluctuation, China, as the demand side, has an impact on the spillover effect. However, the medium- and long-term fluctuations are closely related to the commodity and financial attributes of crude oil. The above conclusions verify the three research hypotheses of this article.

This paper mainly explores the mean spillover effect of international oil price fluctuation on China's stock markets, based on the data of income. The research on risk spillover is relatively less, and further research can be carried out in the next step. Based on the above empirical research results, in the context of the deepening reform of China's stock market and the significant increase in the uncertainty of the crude oil market, in order to better cope with the impact of the international oil market, China needs to analyze more accurately and grasp the dynamic spillover difference of 
international oil price fluctuation, fully combine the long-term fluctuation trend and short-term fluctuation agglomeration, and build a more scientific and reasonable structure. Secondly, China needs to steadily promote the reform of the stock market, enrich the stock market varieties, and promote the orderly and stable operation of the stock market and the deep integration with the international market. Finally, China needs to vigorously promote the development of derivative financial products, such as crude oil futures. We should enhance China's voice in international crude oil pricing, vigorously promote the emergence of stocks in related industries such as crude oil, and enhance the risk prevention and control ability of China's stock market.

Author Contributions: Conceptualization, J.Z. and Q.S.; methodology, J.Z.; software, J.Z.; validation, J.Z., Q.S. and D.S.; formal analysis, J.Z.; investigation, J.Z.; resources, J.Z.; data curation, J.Z.; writing—original draft preparation, J.Z..; writing - review and editing, J.Z.; visualization, D.S.; supervision, J.Z.; project administration, J.Z.; funding acquisition, Q.S. All authors have read and agreed to the published version of the manuscript.

Funding: This research was funded by the National Natural Science Foundation of China (71801226).

Acknowledgments: The authors are grateful to the reviewers and editors for helpful comments and suggestions.

Conflicts of Interest: The authors declare no conflict of interest.

\section{Appendix A}

Table A1. Model recognition.

\begin{tabular}{cccc}
\hline & $\log (\mathbf{L})$ & AIC & SC \\
\hline GARCH $(1,1)$ & 8905.961 & -4.947405 & -4.925031 \\
EGARCH $(1,1)$ & 8945.225 & -4.968693 & -4.944598 \\
GJR-GARCH $(1,1)$ & 8937.777 & -4.964549 & -4.940454 \\
LGARCH $(1,1)$ & 8907.726 & -4.947831 & -4.923735 \\
TGARCH $(1,1)$ & 8926.472 & -4.95321 & -4.937914 \\
VGARCH $(1,1)$ & 8916.509 & -4.949598 & -4.925781 \\
\hline
\end{tabular}

Notes: GJR-GARCH indicates glosten jagannathan runkle-generalized autoregressive conditional heteroskedasticity. LGARCH indicates log generalized autoregressive conditional heteroskedasticity. TGARCH indicates threshold generalized autoregressive conditional heteroskedasticity. VGARCH indicates vector generalized autoregressive conditional heteroskedasticity.

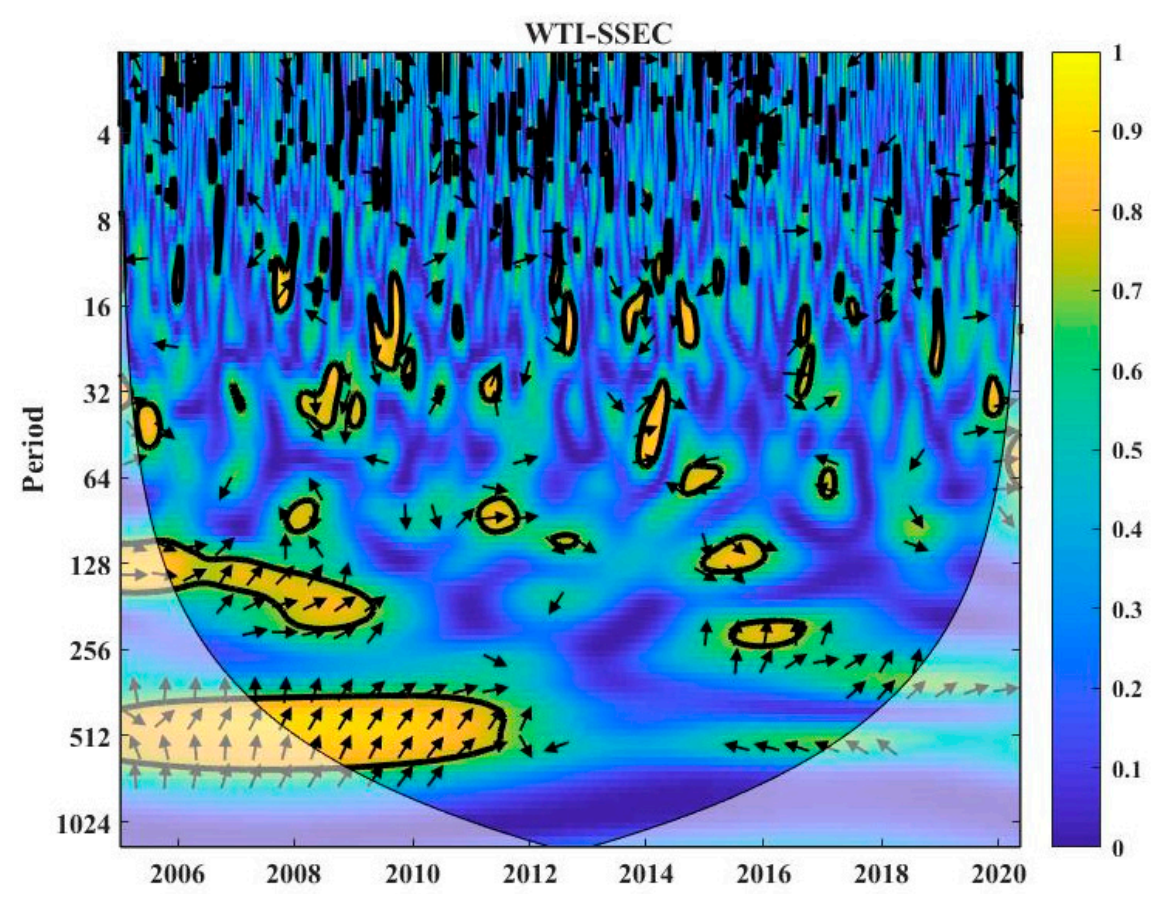

Figure A1. Wavelet coherent frequency spectra of WTI spot price and the Shanghai Composite Index. 
Table A2. Estimates of t-Copula for short-term trend between Brent spot price and the stock indexes of China Securities Industry.

\begin{tabular}{|c|c|c|c|c|c|c|c|c|c|c|}
\hline & CSIE & CSIMA & CSII & CSIO & CSIC & CSIME & CSIF & CSIIN & CSIT & CSIPU \\
\hline \multicolumn{11}{|c|}{ Static Student-t-Copula parameters } \\
\hline \multirow{2}{*}{$\rho$} & $0.052^{* * *}$ & $0.062^{* * *}$ & $0.062^{* * *}$ & $0.049^{* * *}$ & $0.070^{* * *}$ & $0.061^{* * *}$ & $0.050 * * *$ & $0.051^{* * *}$ & $0.042 * *$ & $0.056^{* * *}$ \\
\hline & $(-0.018)$ & $(-0.018)$ & $(-0.018)$ & $(-0.018)$ & $(-0.017)$ & $(-0.018)$ & $(-0.018)$ & $(-0.018)$ & $(-0.019)$ & $(-0.018)$ \\
\hline \multirow{2}{*}{ DOF } & 30.167 & 199.953 & $135.249^{* * *}$ & $65.583^{* * *}$ & $79.717^{* * *}$ & $37.686^{* *}$ & $27.811^{* *}$ & $30.596^{* *}$ & 53.285 & $199.988^{* * *}$ \\
\hline & (22.990) & $(2.767)$ & (29.777) & (9.976) & (10.685) & (15.932) & (15.492) & $(14.852)$ & (48.455) & (32.646) \\
\hline $\log (\mathrm{L})$ & 6.253 & 7.466 & 7.480 & 5.382 & 8.513 & 7.480 & 6.099 & 4.724 & 3.326 & 5.964 \\
\hline AIC & -10.506 & -12.931 & -12.959 & -8.765 & -15.026 & -12.960 & -10.198 & -7.448 & -4.651 & -9.927 \\
\hline \multicolumn{11}{|c|}{ DCC-Student-t-Copula parameters } \\
\hline \multirow{2}{*}{$\rho$} & $0.050 * * *$ & $0.063^{* * *}$ & $0.063 * * *$ & $0.051^{* * *}$ & $0.067^{* * *}$ & $0.058^{* * *}$ & $0.048^{* * *}$ & $0.043^{* * * *}$ & $0.039^{* * *}$ & $0.057^{* * * *}$ \\
\hline & $(0.004)$ & $(0.004)$ & $(0.004)$ & $(0.004)$ & $(0.004)$ & $(0.004)$ & $(0.004)$ & $(0.004)$ & $(0.004)$ & $(0.004)$ \\
\hline \multirow{2}{*}{ DOF } & $50.687^{* * *}$ & $199.929^{* * *}$ & $197.640^{* *}$ & 199.962 & $199.908^{* * *}$ & 199.973 & $86.229 * * *$ & 199.759 & 199.978 & 200.000 \\
\hline & (14.891) & (4.380) & (96.289) & (839.122) & (3.140) & (1990.256) & (20.625) & $(330.381)$ & $(2827.011)$ & (3.145) \\
\hline \multirow[b]{2}{*}{$\alpha$} & $0.338^{* * *}$ & $0.314^{* * *}$ & $0.310^{* * *}$ & $0.305^{* * *}$ & $0.317^{* * *}$ & 0.318 & $0.325^{* * *}$ & $0.325^{* * *}$ & 0.327 & $0.305^{* * *}$ \\
\hline & $(0.019)$ & $(0.018)$ & $(0.020)$ & $(0.072)$ & $(0.019)$ & $(0.581)$ & $(0.020)$ & $(0.033)$ & $(2.780)$ & $(0.019)$ \\
\hline \multirow{2}{*}{$\beta$} & $0.117^{* *}$ & 0.151 ** & 0.068 & 0.075 & 0.000 & 0.054 & 0.000 & $0.124^{*}$ & 0.101 & 0.060 \\
\hline & $(0.053)$ & $(0.065)$ & $(0.070)$ & $(0.970)$ & $(0.122)$ & (3.668) & $(0.101)$ & $(0.074)$ & (3.781) & $(0.061)$ \\
\hline $\log (\mathrm{L})$ & 166.904 & 150.145 & 147.518 & 144.007 & 155.677 & 159.633 & 166.098 & 156.638 & 155.362 & 143.620 \\
\hline AIC & -327.807 & -294.290 & -289.037 & -282.015 & -305.354 & -313.265 & -326.196 & -307.276 & -304.724 & -281.240 \\
\hline
\end{tabular}

Notes: This table reports the estimates of static Student-t-Copula and DCC-Student-t-Copula based on decomposed return series characterizing the short-term investment horizon between

Brent spot crude oil and the stock index of China Securities Industry. Standard errors are presented in parenthesis. *,**, and ${ }^{* * *}$ represent statistical significance at the $10 \%$ level, at the $5 \%$

level, and at the $1 \%$ level, respectively. 
Table A3. Estimates of t-Copula for mid-term trend between Brent spot price and the stock indexes of China Securities Industry.

\begin{tabular}{|c|c|c|c|c|c|c|c|c|c|c|}
\hline & CSIE & CSIMA & CSII & CSIO & CSIC & CSIME & CSIF & CSIIN & CSIT & CSIPU \\
\hline \multicolumn{11}{|c|}{ Static Student-t-Copula parameters } \\
\hline \multirow[b]{2}{*}{$\rho$} & $0.215 * * *$ & $0.163^{* * *}$ & $0.145 * * *$ & $0.133^{* * *}$ & $0.129 * * *$ & $0.105^{* * *}$ & $0.170^{* * *}$ & $0.151^{* * *}$ & $0.071^{* * *}$ & $0.066^{* * * *}$ \\
\hline & $(-0.016)$ & $(-0.017)$ & $(-0.017)$ & $(-0.017)$ & $(-0.017)$ & $(-0.017)$ & $(-0.017)$ & $(-0.017)$ & $(-0.017)$ & $(-0.017)$ \\
\hline \multirow{2}{*}{ DOF } & 100.121 & 36.558 & $168.019 * * *$ & $19.427 * *$ & $199.996^{* * *}$ & 199.950 & $200.000^{* * *}$ & $24.737^{* *}$ & $27.803 * *$ & 199.980 \\
\hline & (135.661) & (31.692) & (3.025) & (8.075) & (35.291) & (488.769) & (16.884) & (11.907) & $(11.564)$ & (162.293) \\
\hline $\log (\mathrm{L})$ & 54.246 & 35.264 & 27.085 & 28.336 & 21.680 & 10.028 & 31.763 & 34.193 & 6.373 & 5.400 \\
\hline AIC & -106.492 & -68.528 & -52.171 & -54.672 & -41.359 & -18.056 & -61.525 & -66.385 & -10.745 & -8.800 \\
\hline \multicolumn{11}{|c|}{ DCC-Student-t-Copula parameters } \\
\hline$\rho$ & $\begin{array}{c}0.189^{* * *} \\
(0.007)\end{array}$ & $\begin{array}{c}0.147^{* * *} \\
(0.008)\end{array}$ & $\begin{array}{c}0.129^{* * *} \\
(0.008)\end{array}$ & $\begin{array}{c}0.121 * * * \\
(0.008)\end{array}$ & $0.116^{* * *}$ & $0.093^{* * *}$ & $0.152^{* * *}$ & $0.146^{* * *}$ & $0.061^{* * *}$ & $0.065^{* * *}$ \\
\hline \multirow{2}{*}{ DOF } & $199.997^{* * *}$ & $199.972 * * *$ & $199.995^{* * *}$ & 200.000 & $199.997 * * *$ & $199.997^{* * *}$ & 200.000 & $29.580^{* *}$ & $199.997 * * *$ & $\begin{array}{l}(0.009) \\
91.835\end{array}$ \\
\hline & $(22.490)$ & $(31.856)$ & $(27.313)$ & $(230.155)$ & (3.347) & (3.690) & $(208.628)$ & $(14.225)$ & (12.183) & (390.177) \\
\hline \multirow[b]{2}{*}{$\alpha$} & $0.500 * * *$ & $0.500^{* * *}$ & $0.500^{* * *}$ & $0.500^{* * *}$ & $0.500^{* * *}$ & $0.500^{* * * *}$ & $0.500^{* * *}$ & $0.186^{* * *}$ & $0.500^{* * *}$ & 0.257 \\
\hline & $(0.019)$ & $(0.075)$ & $(0.035)$ & $(0.060)$ & $(0.022)$ & $(0.023)$ & $(0.029)$ & $(0.018)$ & $(0.022)$ & $(0.197)$ \\
\hline \multirow{2}{*}{$\beta$} & $0.263^{* * *}$ & 0.319 ** & $0.316^{* *}$ & $0.321^{* * *}$ & $0.268^{* * *}$ & $0.290^{* * *}$ & $0.316^{* * *}$ & $0.796^{* * *}$ & $0.291^{* * *}$ & $0.699 * *$ \\
\hline & $(0.036)$ & $(0.124)$ & $(0.061)$ & $(0.101)$ & $(0.034)$ & $(0.038)$ & $(0.049)$ & $(0.023)$ & $(0.039)$ & $(0.286)$ \\
\hline $\log (\mathrm{L})$ & 808.200 & 902.390 & 873.549 & 928.625 & 803.379 & 828.612 & 851.719 & 913.556 & 853.109 & 898.159 \\
\hline AIC & -1610.400 & -1798.781 & -1741.098 & -1851.249 & -1600.759 & -1651.224 & -1697.439 & -1821.113 & -1700.219 & -1790.318 \\
\hline
\end{tabular}

Notes: This table reports the estimates of static Student-t-Copula and DCC-Student-t-Copula based on decomposed return series characterizing the mid-term investment horizon between

Brent spot crude oil and the stock index of China Securities Industry. Standard errors are presented in parenthesis. ${ }^{* *}$, and ${ }^{* * *}$ represent statistical significance at the $5 \%$ level, and at the $1 \%$

level, respectively. 
Table A4. Estimates of t-Copula for long-term trend between Brent spot price and the stock indexes of China Securities Industry.

\begin{tabular}{|c|c|c|c|c|c|c|c|c|c|c|}
\hline & CSIE & CSIMA & CSII & CSIO & CSIC & CSIME & CSIF & CSIIN & CSIT & CSIPU \\
\hline \multicolumn{11}{|c|}{ Static Student-t-Copula parameters } \\
\hline$\rho$ & $\begin{array}{c}0.259^{* * *} \\
(0.016)\end{array}$ & $\begin{array}{c}0.215^{* * *} \\
(0.016)\end{array}$ & $\begin{array}{c}0.073^{* * *} \\
(0.016)\end{array}$ & $\begin{array}{c}0.216^{* * *} \\
(0.016)\end{array}$ & $\begin{array}{c}0.423 * * * \\
(0.016)\end{array}$ & $\begin{array}{c}0.247^{* * * *} \\
(0.016)\end{array}$ & $\begin{array}{c}0.153^{* * *} \\
(0.016)\end{array}$ & $\begin{array}{c}0.217^{* * * *} \\
(0.016)\end{array}$ & $\begin{array}{c}0.112 * * * \\
(0.016)\end{array}$ & $\begin{array}{c}0.015 \\
(0.050)\end{array}$ \\
\hline DOF & $\begin{array}{c}6.273^{* * *} \\
(0.723)\end{array}$ & $\begin{array}{c}9.212^{* * *} \\
(1.498)\end{array}$ & $\begin{array}{c}14.907^{* * *} \\
(3.589)\end{array}$ & $\begin{array}{c}7.951^{* * *} \\
(0.984)\end{array}$ & $\begin{array}{c}9.698^{* * *} \\
(1.396)\end{array}$ & $\begin{array}{c}5.265^{* * *} \\
(0.544)\end{array}$ & $\begin{array}{c}24.985^{* *} \\
(11.090)\end{array}$ & $\begin{array}{c}7.784^{* * *} \\
(0.958)\end{array}$ & $\begin{array}{c}6.297 * * * \\
(0.800)\end{array}$ & $\begin{array}{c}199.999 * * \\
(7.710)\end{array}$ \\
\hline $\log (\mathrm{L})$ & 137.750 & 77.286 & 9.389 & 79.149 & 284.857 & 153.642 & 27.284 & 86.832 & 47.629 & -1.370 \\
\hline AIC & -273.500 & -152.571 & -16.779 & -156.297 & -567.714 & -305.284 & -52.569 & -171.664 & -93.257 & 4.739 \\
\hline \multicolumn{11}{|c|}{ DCC-Student-t-Copula parameters } \\
\hline$\rho$ & $\begin{array}{c}0.258^{* * *} \\
(0.010)\end{array}$ & $\begin{array}{c}0.213^{* * *} \\
(0.010)\end{array}$ & $\begin{array}{c}0.083^{* * *} \\
(0.009)\end{array}$ & $\begin{array}{c}0.202 * * * \\
(0.009)\end{array}$ & $\begin{array}{c}0.374^{* * *} \\
(0.006)\end{array}$ & $\begin{array}{c}0.226^{* * *} \\
(0.009)\end{array}$ & $\begin{array}{c}0.155^{* * *} \\
(0.009)\end{array}$ & $\begin{array}{c}0.198^{* * *} \\
(0.010)\end{array}$ & $\begin{array}{c}0.101 \text { *** } \\
(0.010)\end{array}$ & $\begin{array}{c}0.050 * * * \\
(0.010)\end{array}$ \\
\hline DOF & $\begin{array}{c}199.989^{* * *} \\
(1.486)\end{array}$ & $\begin{array}{c}199.938^{* * *} \\
(10.210)\end{array}$ & $\begin{array}{c}198.798 * * * \\
(1.512)\end{array}$ & $\begin{array}{c}199.997^{* * *} \\
(1.462)\end{array}$ & $\begin{array}{c}199.982 * * * \\
(15.296)\end{array}$ & $\begin{array}{c}199.986^{* * *} \\
(11.954)\end{array}$ & $\begin{array}{c}199.977^{* *} \\
(79.923)\end{array}$ & $\begin{array}{c}199.024^{* * *} \\
(2.019)\end{array}$ & $\begin{array}{c}200.000 * * * \\
(22.408)\end{array}$ & $\begin{array}{c}199.988 * * \\
(1.447)\end{array}$ \\
\hline$\alpha$ & $\begin{array}{c}0.027^{* * * *} \\
(0.001)\end{array}$ & $\begin{array}{c}0.022 * * * \\
(0.002)\end{array}$ & $\begin{array}{c}0.038^{* * *} \\
(0.008)\end{array}$ & $\begin{array}{c}0.039 \\
(0.051)\end{array}$ & $\begin{array}{c}0.199 \\
(0.165)\end{array}$ & $\begin{array}{c}0.054 \\
(1.122)\end{array}$ & $\begin{array}{c}0.021^{* * *} \\
(0.001)\end{array}$ & $\begin{array}{c}0.028^{* * *} \\
(0.001)\end{array}$ & $\begin{array}{c}0.015^{* * *} \\
(0.001)\end{array}$ & $\begin{array}{c}0.028 \\
(0.041)\end{array}$ \\
\hline$\beta$ & $\begin{array}{c}0.972 * * * \\
(0.001)\end{array}$ & $\begin{array}{c}0.977^{* * *} \\
(0.002)\end{array}$ & $\begin{array}{c}0.958^{* * *} \\
(0.009)\end{array}$ & $\begin{array}{c}0.957^{* * *} \\
(0.083)\end{array}$ & $\begin{array}{l}0.675^{* *} \\
(0.280)\end{array}$ & $\begin{array}{c}0.934 \\
(1.062)\end{array}$ & $\begin{array}{c}0.978^{* * *} \\
(0.001)\end{array}$ & $\begin{array}{c}0.971 * * * \\
(0.001)\end{array}$ & $\begin{array}{c}0.984^{* * *} \\
(0.001)\end{array}$ & $\begin{array}{c}0.970 * * * \\
(0.048)\end{array}$ \\
\hline $\log (\mathrm{L})$ & 1145.849 & 1155.166 & 996.643 & 988.382 & 975.807 & 1185.507 & 891.787 & 1107.444 & 1165.992 & 996.152 \\
\hline AIC & -2285.698 & -2304.331 & -1987.285 & -1970.764 & -1945.614 & -2365.014 & -1777.574 & -2208.888 & -2325.984 & -1986.303 \\
\hline
\end{tabular}

Notes: This table reports the estimates of static Student-t-Copula and DCC-Student-t-Copula based on decomposed return series characterizing the long-term investment horizon between

Brent spot crude oil and the stock index of China Securities Industry. Standard errors are presented in parenthesis. ${ }^{* *}$, and ${ }^{* * *}$ represent statistical significance at the $5 \%$ level, and at the $1 \%$

level, respectively. 
Table A5. Estimates of T-Copula for original returns series between WTI spot price and the stock indexes of China Securities Industry.

\begin{tabular}{|c|c|c|c|c|c|c|c|c|c|c|}
\hline & CSIE & CSIMA & CSII & CSIO & CSIC & CSIME & CSIF & CSIIN & CSIT & CSIPU \\
\hline \multicolumn{11}{|c|}{ Static Student-t-Copula parameters } \\
\hline$\rho$ & $\begin{array}{l}0.109 \text { *** } \\
(-0.017)\end{array}$ & $\begin{array}{l}0.088^{* * *} \\
(-0.017)\end{array}$ & $\begin{array}{l}0.095^{* * *} \\
(-0.017)\end{array}$ & $\begin{array}{l}0.088^{* * *} \\
(-0.017)\end{array}$ & $\begin{array}{l}0.068^{* * *} \\
(-0.017)\end{array}$ & $\begin{array}{l}0.070^{* * *} \\
(-0.017)\end{array}$ & $\begin{array}{l}0.091^{* * *} \\
(-0.017)\end{array}$ & $\begin{array}{l}0.070^{* * *} \\
(-0.017)\end{array}$ & $\begin{array}{l}0.069^{* * *} \\
(-0.017)\end{array}$ & $\begin{array}{l}0.086^{* * *} \\
(-0.017)\end{array}$ \\
\hline DOF & $\begin{array}{c}16.206^{* * *} \\
(5.011)\end{array}$ & $\begin{array}{c}13.913^{* * *} \\
(3.561)\end{array}$ & $\begin{array}{c}15.158^{* * *} \\
(4.071)\end{array}$ & $\begin{array}{c}13.897^{* * *} \\
(3.948)\end{array}$ & $\begin{array}{c}18.810^{* *} \\
(7.551)\end{array}$ & $\begin{array}{c}14.953^{* * *} \\
(3.840)\end{array}$ & $\begin{array}{c}13.484^{* * *} \\
(3.307)\end{array}$ & $\begin{array}{c}16.204^{* * *} \\
(5.086)\end{array}$ & $\begin{array}{c}18.313^{* *} \\
(7.664)\end{array}$ & $\begin{array}{c}16.728^{* * *} \\
(4.953)\end{array}$ \\
\hline $\log (\mathrm{L})$ & 33.231 & 26.078 & 26.340 & 25.883 & 16.702 & 19.583 & 27.360 & 18.688 & 17.279 & 22.340 \\
\hline AIC & -64.461 & -50.157 & -50.680 & -49.767 & -31.404 & -37.167 & -52.720 & -35.377 & -32.558 & -42.680 \\
\hline \multicolumn{11}{|c|}{ DCC-Student-t-Copula parameters } \\
\hline$\rho$ & $\begin{array}{c}0.120^{* * * *} \\
(0.001)\end{array}$ & $\begin{array}{c}0.097^{* * * *} \\
(0.001)\end{array}$ & $\begin{array}{c}0.103^{* * *} \\
(0.001)\end{array}$ & $\begin{array}{c}0.099^{* * * *} \\
(0.001)\end{array}$ & $\begin{array}{c}0.083^{* * *} \\
(0.001)\end{array}$ & $\begin{array}{c}0.085^{* * * *} \\
(0.001)\end{array}$ & $\begin{array}{c}0.097^{* * *} \\
(0.001)\end{array}$ & $\begin{array}{c}0.084^{* * *} \\
(0.001)\end{array}$ & $\begin{array}{c}0.086^{* * *} \\
(0.001)\end{array}$ & $\begin{array}{c}0.096^{* * *} \\
(0.001)\end{array}$ \\
\hline DOF & $\begin{array}{c}18.565^{* * *} \\
(6.072)\end{array}$ & $\begin{array}{c}15.936^{* * *} \\
(4.974)\end{array}$ & $\begin{array}{c}16.083^{* * *} \\
(4.273)\end{array}$ & $\begin{array}{c}14.798^{* * *} \\
(4.220)\end{array}$ & $\begin{array}{c}20.405^{* *} \\
(9.110)\end{array}$ & $\begin{array}{c}15.439^{* * * *} \\
(4.170)\end{array}$ & $\begin{array}{c}14.618^{* * *} \\
(3.674)\end{array}$ & $\begin{array}{c}17.919^{* * *} \\
(6.067)\end{array}$ & $\begin{array}{c}19.344^{* *} \\
(6.995)\end{array}$ & $\begin{array}{c}16.948^{* * *} \\
(5.569)\end{array}$ \\
\hline$\alpha$ & $\begin{array}{c}0.006 \\
(0.004)\end{array}$ & $\begin{array}{l}0.007^{*} \\
(0.004)\end{array}$ & $\begin{array}{c}0.015^{* *} \\
(0.006)\end{array}$ & $\begin{array}{c}0.015^{* * *} \\
(0.006)\end{array}$ & $\begin{array}{l}0.010^{*} \\
(0.006)\end{array}$ & $\begin{array}{c}0.010^{*} \\
(0.006)\end{array}$ & $\begin{array}{l}0.005^{*} \\
(0.003)\end{array}$ & $\begin{array}{c}0.014^{* *} \\
(0.006)\end{array}$ & $\begin{array}{c}0.036^{* *} \\
(0.017)\end{array}$ & $\begin{array}{c}0.017^{* *} \\
(0.008)\end{array}$ \\
\hline$\beta$ & $\begin{array}{c}0.990^{* * *} \\
(0.011)\end{array}$ & $\begin{array}{c}0.989^{* * *} \\
(0.009)\end{array}$ & $\begin{array}{c}0.954^{* * *} \\
(0.025)\end{array}$ & $\begin{array}{c}0.939^{* * *} \\
(0.024)\end{array}$ & $\begin{array}{c}0.950 * * * \\
(0.034)\end{array}$ & $\begin{array}{c}0.941^{* * *} \\
(0.037)\end{array}$ & $\begin{array}{c}0.990^{* * *} \\
(0.009)\end{array}$ & $\begin{array}{c}0.946^{* * *} \\
(0.024)\end{array}$ & $\begin{array}{c}0.000 \\
(0.320)\end{array}$ & $\begin{array}{c}0.938^{* * *} \\
(0.032)\end{array}$ \\
\hline $\log (\mathrm{L})$ & 39.853 & 35.827 & 33.699 & 30.524 & 19.354 & 21.811 & 34.079 & 23.481 & 19.861 & 28.169 \\
\hline AIC & -73.705 & -65.655 & -61.398 & -55.048 & -32.709 & -37.623 & -62.158 & -40.961 & -33.722 & -50.337 \\
\hline
\end{tabular}

Notes: This table reports the estimates of static Student-t-Copula and DCC-Student-t-Copula for original returns series between Brent spot crude oil and the stock index of China Securities Industry. Standard errors are presented in parenthesis. ${ }^{*}, * *$, and ${ }^{* * *}$ represent statistical significance at the $10 \%$ level, at the $5 \%$ level, and at the $1 \%$ level, respectively. 


\section{References}

1. Kolodziej, M.; Kaufmann, R.K.; Kulatilaka, N.; Bicchetti, D.; Maystre, N. Crude oil: Commodity or financial asset? Energy Econ. 2014, 46, 216-223. [CrossRef]

2. Antolin-Lopez, R.; Martinez-del-Rio, J.; Cespedes-Lorente, J. Environmental entrepreneurship as a multi-component and dynamic construct: Duality of goals, environmental agency, and environmental value creation. Bus. Ethics 2019, 28, 407-422. [CrossRef]

3. Lee, B.J.; Yang, C.W.; Huang, B.N. Oil price movements and stock markets revisited: A case of sector stock price indexes in the G7 countries. Energy Econ. 2012, 34, 1284-1300. [CrossRef]

4. Ahmed, K.; Bhutto, N.A.; Kalhoro, M.R. Decomposing the links between oil price shocks and macroeconomic indicators: Evidence from SAARC region. Resour. Policy 2019, 61, 423-432. [CrossRef]

5. Azimli, A. The oil price risk and global stock returns. Energy 2020, 198, 1-9. [CrossRef]

6. Fang, S.; Egan, P. Measuring contagion effects between crude oil and Chinese stock market sectors. Q. Rec. Econ. Financ. 2018, 68, 31-38. [CrossRef]

7. Yu, W.; Qin, S.K.; Li, X.F.; Zhu, S.; Wei, G.W. Oil price fluctuation, stock market and macroeconomic fundamentals: Evidence from China before and after the financial crisis. Financ. Res. Lett. 2019, 30, $23-29$.

8. Gu, F.; Wang, J.Q.; Guo, J.F.; Fan, Y. Dynamic linkages between international oil price, plastic stock index and recycle plastic markets in China. Int. Rev. Econ. Financ. 2020, 68, 167-179. [CrossRef]

9. Sakellaris, P. Irreversible capital and the stock market response to shocks in profitability. Int. Econ. Rev. 1997, 21, 351-379. [CrossRef]

10. Wei, C. Energy, the stock market, and the putty-clay investment model. Am. Econ. Rev. 2003, 93, 311-323. [CrossRef]

11. Antonakakis, N.; Chatziantoniou, I.; Fills, G. Oil shocks and stock markets: Dynamic connectedness under the prism of recent geopolitical and economic unrest. Int. Rev. Financ. Anal. 2017, 50, 1-26. [CrossRef]

12. Olarte, J.; Gisbert-Trejo, N.; Ferret-Poza, R.; Zulueta, E. Energy storage: Keys for Europe in the coming years. DYNA 2019, 94, 592-597. [CrossRef]

13. Hoque, M.E.; Zaidi, M.A. The impacts of global economic policy uncertainty on stock market returns in regime switching environment: Evidence from sectoral perspectives. Int. J. Financ. Econ. 2019, 24, 991-1016.

14. Jesus, D.P.; Bezerra, B.F.; Besarria, C.N. The non-linear relationship between oil prices and stock prices: Evidence from oil-importing and oil-exporting countries. Res. Int. Bus. Financ. 2020, 54, 1-14. [CrossRef]

15. Huang, R.D.; Masulis, R.W.; Stoll, H.R. Energy shocks and financial markets. J. Futures Mark. 1996, 16, 1-27. [CrossRef]

16. Jones, C.M.; Kaul, G. Oil and the Stock Markets. J. Financ. 1996, 51, 463-491. [CrossRef]

17. Park, J.; Ratti, R.A. Oil price shocks and stock markets in the U.S. and 13 European countries. Energy Econ. 2008, 30, 2587-2608. [CrossRef]

18. Samanta, N. Transplantation of Anglo-American corporate governance and its impact on financial market growth: A comparative analysis of nineteen developing countries 1995-2014. Corp. Gov. Int. J. Bus. Soc. 2019, 19, 884-922. [CrossRef]

19. Shahrestani, P.; Rafei, M. The impact of oil price shocks on tehran stock exchange returns: Application of the Markov switching vector autoregressive models. Resour. Policy 2020, 65, 15-24. [CrossRef]

20. Jamali, D.; Barkemeyer, R.; Leigh, J.; Samara, G. Open access, open science, and coronavirus: Mega trends with historical proportions. Bus. Ethics 2020, 29, 419-421. [CrossRef]

21. Kilian, L. Not all oil price shocks are alike: Disentangling demand and supply shocks in the crude oil market. Am. Econ. Rev. 2009, 99, 1053-1069. [CrossRef]

22. Kang, W.; Ratti, R.A. Oil shocks, policy uncertainty and stock market return. J. Int. Financ. Mark. Inst. Money 2013, 26, 305-318. [CrossRef]

23. Broadstock, D.C.; Filis, G. Oil price shocks and stock market returns: New evidence from the United States and China. J. Int. Financ. Mark. Inst. Money 2014, 33, 417-433. [CrossRef]

24. Ready, R.C. Oil prices and the stock market. Rev. Financ. 2018, 22, 155-176. [CrossRef]

25. Aloui, R.; Aissa, M.S.B.; Nguyen, D.K. Conditional dependence structure between oil prices and exchange rates: A copula-GARCH approach. J. Int. Money Financ. 2013, 32, 719-738. [CrossRef]

26. Jia, X.; An, H.; Fang, W.; Sun, X.; Huang, X. How do correlations of crude oil prices co-move? A grey correlation-based wavelet perspective. Energy Econ. 2016, 49, 588-598. [CrossRef] 
27. Huang, S.; An, H.; Gao, X.; Sun, X. Do oil price asymmetric effects on the stock market persist in multiple time horizons? Appl. Energy 2017, 25, 18-32. [CrossRef]

28. Sarwar, S.; Tiwari, A.K.; Cao, T.Q. Analyzing volatility spillovers between oil market and Asian stock markets. Resour. Policy 2020, 66, 1-12. [CrossRef]

29. Yahya, M.; Oglend, A.; Dahl, R.E. Temporal and spectral dependence between crude oil and agricultural commodities: A wavelet-based copula approach. Energy Econ. 2019, 80, 277-296. [CrossRef]

30. Feng, Y.; Xu, D.; Failler, P.; Li, T. Research on the Time-Varying Impact of Economic Policy Uncertainty on Crude Oil Price Fluctuation. Sustainability 2020, 12, 6523. [CrossRef]

31. Torrence, C.; Compo, G.P. A practical guide to wavelet analysis. Bull. Am. Meteorol. Soc. 1998, 79, 61-78. [CrossRef]

32. Yang, L.; Cai, X.J.; Hamori, S. Does the crude oil price influence the exchange rates of oil-importing and oil-exporting countries differently? A wavelet coherence analysis. Int. Rev. Econ. Financ. 2017, 49, 536-547. [CrossRef]

33. Nelson, D.B. Conditional heteroskedasticity in asset returns: A new approach. Econometrica 1991, 59, 347-370. [CrossRef]

34. Bekiros, S.D.; Nguyen, D.K.; Junior, L.S.; Uddin, G.S. Information diffusion, cluster formation and entropy-based network dynamics in equity and commodity markets. Eur. J. Oper. Res. 2017, 256, 945-961. [CrossRef]

35. Berger, T.; Uddin, G.S. On the dynamic dependence between equity markets, commodity futures and economic uncertainty indexes. Energy Econ. 2016, 56, 374-383. [CrossRef]

36. Daubechies, I. Ten Lectures on Wavelets; Society for Industrial and Applied Mathematics: Philadelphia, PA, USA, 1992; pp. 115-140.

37. Orazalin, N.; Mahmood, M. The financial crisis as a wake-up call: Corporate governance and bank performance in an emerging economy. Corp. Gov. 2019, 19, 80-101. [CrossRef]

38. Simpson, S.N.; Aprim, F. Do corporate social responsibility practices of firms attract prospective employees? Perception of university students from a developing country. Int. J. Corp. Soc. Res. 2018, 3, 1-11. [CrossRef]

39. Korotin, V.; Dolgonosov, M.; Popov, V.; Korotina, O.; Korolkova, I. The Ukrainian crisis, economic sanctions, oil shock and commodity currency: Analysis based on EMD approach. Res. Int. Bus. Financ. 2019, 48, 156-168. [CrossRef]

40. Bosnjakovic, M.; Tadijanovic, V. Environment impact of a concentrated solar power plant. Tehnički Glasnik 2019, 13, 68-74. [CrossRef]

41. Lv, X.; Lien, D.; Yu, C. Who affects who? Oil price against the stock return of oil-related companies: Evidence from the U.S. and China. Int. Rev. Econ. Financ. 2020, 67, 85-100. [CrossRef]

42. Strotmann, H.; Volkert, J.; Schmidt, M. Multinational companies: Can they foster well-being in the eyes of the poor? Results from an empirical case study. Int. J. Corp. Soc. Res. 2019, 4, 1-14. [CrossRef]

43. Sorli-Pena, M.; Parra-Gomez, A. China in context: Current situation, strategies and uncertainties. Dyna 2020, 95, 233-236.

44. Aksu, U.; Halicioglu, R. A review study on energy harvesting systems for vehicles. Tehnički Glasnik Tech. J. 2018, 12, 251-259. [CrossRef]

45. Zhang, X.; Zhao, Y.; Qi, R.; Usman, M. The impact of bank competition on stock price crash risk: Evidence from the Chinese market. Transform. Bus. Econ. 2019, 18, 900-920.

46. Arendas, P.; Tkacova, D.; Bukoven, J. Seasonal patterns in oil prices and their implications for investors. J. Int. Stud. 2018, 11, 180-192. [CrossRef] [PubMed]

47. Loganathan, N.; Streimikiene, D.; Mursitama, T.N.; Shahbaz, M.; Mardani, A. How real oil prices and domestic financial instabilities are good for GCC countries tourism demand in Malaysia? Econ. Sociol. 2018, 11, 112-125. [CrossRef]

48. Lu, J.T.; Ren, L.C.; Yao, S.Q.; Rong, D.; Skare, M.; Streimikis, J. Renewable energy barriers and coping strategies: Evidence from the Baltic States. Sustain. Dev. 2020, 28, 352-367. [CrossRef]

49. Lu, J.T.; Ren, L.C.; Yao, S.Q.; Qiao, J.Y.; Mikalauskiene, A.; Streimikis, J. Exploring the relationship between corporate social responsibility and firm competitiveness. Econ. Res. Ekon Istraz 2020, 33, 1621-1646. [CrossRef]

(C) 2020 by the authors. Licensee MDPI, Basel, Switzerland. This article is an open access article distributed under the terms and conditions of the Creative Commons Attribution (CC BY) license (http://creativecommons.org/licenses/by/4.0/). 